NBER WORKING PAPER SERIES

\title{
FOREIGN SHOCKS AS GRANULAR FLUCTUATIONS
}

\author{
Julian di Giovanni \\ Andrei A. Levchenko \\ Isabelle Mejean \\ Working Paper 28123 \\ http://www.nber.org/papers/w28123
NATIONAL BUREAU OF ECONOMIC RESEARCH
1050 Massachusetts Avenue
Cambridge, MA 02138 \\ November 2020, Revised September 2022
}

We are grateful to the editor (Harald Uhlig), three anonymous referees, David Atkin, Ariel Burstein, Javier Cravino, Xavier Gabaix, Basile Grassi, Oleg Itskhoki, Dominik Menno, Dimitrije Ruzic, Sebastian Sotelo, and seminar participants at several institutions for helpful suggestions, and to Pierre Coster, Christopher Evans, and William Haines for expert research assistance. Di Giovanni gratefully acknowledges the European Research Council (ERC) under the European Union's Horizon 2020 research and innovation programme (grant agreement No. 726168), and the Spanish Ministry of Economy and Competitiveness, through the Severo Ochoa Programme for Centres of Excellence in R\&D (SEV-2015-0563) for financial support. Mejean gratefully acknowledges support from a public grant overseen by the French National Research Agency (ANR) as part of the "Investissements d'Avenir" program (Idex Grant Agreement No. ANR-11IDEX-0003- 02/Labex ECODEC No. ANR-11-LABEX-0047 and Equipex reference: ANR-10EQPX-17 - Centre d'accès sécurisé aux données - CASD) as well as the European Research Council (ERC) under the European Union's Horizon 2020 research and innovation programme (grant agreement No. 714597). The views expressed herein are those of the authors and not necessarily those of the Federal Reserve Bank of New York or the National Bureau of Economic Research.

NBER working papers are circulated for discussion and comment purposes. They have not been peer-reviewed or been subject to the review by the NBER Board of Directors that accompanies official NBER publications.

(C) 2020 by Julian di Giovanni, Andrei A. Levchenko, and Isabelle Mejean. All rights reserved. Short sections of text, not to exceed two paragraphs, may be quoted without explicit permission provided that full credit, including (C) notice, is given to the source. 
Foreign Shocks as Granular Fluctuations

Julian di Giovanni, Andrei A. Levchenko, and Isabelle Mejean

NBER Working Paper No. 28123

November 2020, Revised September 2022

JEL No. E32,F15,F23,F44,F62,L14

\begin{abstract}
$\underline{\text { ABSTRACT }}$
This paper uses a dataset covering the universe of French firm-level value added, imports, and exports over the period 1995-2007 and a quantitative multi-country model to study the international transmission of business cycle shocks at both the micro and the macro levels. Because the largest firms are the most likely to trade internationally, foreign shocks are transmitted to the domestic economy primarily through the large firms. We first document a novel stylized fact: larger French firms are significantly more sensitive to foreign GDP growth. We then implement a quantitative framework calibrated to the full extent of the observed heterogeneity in firm size, exporting, and importing. We simulate the propagation of foreign shocks to the French economy and report one micro and one macro finding. At the micro level heterogeneity across firms predominates: 45 to $75 \%$ of the impact of foreign fluctuations on French GDP is accounted for by the "foreign granular residual" - the term capturing the larger firms' greater responsiveness to the foreign shocks. At the macro level, firm heterogeneity attenuates the impact of foreign shocks, with the GDP responses 10 to $20 \%$ larger in a representative firm model compared to the baseline model.
\end{abstract}

Julian di Giovanni

Research and Statistics Group

Federal Reserve Bank of New York

33 Liberty Street

New York, NY 10045

and CEPR

juliandigiovanni@gmail.com

Andrei A. Levchenko

Department of Economics

University of Michigan

611 Tappan Street

Ann Arbor, MI 48109

and CEPR

and also NBER

alev@umich.edu
Isabelle Mejean

Département d'Economie

Sciences Po

28 rue des Saints PÃ ${ }^{\prime}$ res

Paris 75006

France

isabelle.mejean@sciencespo.fr 


\section{Introduction}

After decades of globalization, production has become a global activity, with supply chains overlapping with country borders. Participation in the global supply chains exposes countries to foreign shocks, which can have a sizable impact on the domestic economy, evidenced most recently by the well-publicized pandemic-related supply chain disruptions. A key feature of the internationalization of production is that the largest firms are responsible for the bulk of cross-border trade linkages in a typical economy (e.g., Freund and Pierola, 2015). As a result, while only a minority of firms have direct trade linkages with foreign countries, those firms account for a large share of aggregate economic activity (di Giovanni et al., 2017, 2018).

We study the consequences of this observed heterogeneity for international shock transmission. Our analysis combines a dataset covering the universe of French firm-level value added and countryspecific imports and exports over the period 1995-2007 and a quantitative multi-country multisector model with heterogeneous firms. We report a novel reduced-form stylized fact, one micro finding, and one macro finding. In the data, larger French firms are significantly more sensitive to foreign GDP growth. Our quantitative exercises show that at the micro level, foreign shocks are granular fluctuations: GDP changes following a foreign shock are driven primarily by the large firms. At the macro level, observed heterogeneity across firms attenuates the aggregate impact of foreign shocks. All in all, our main conclusion is that the firm-level differential exposures to trade are quantitatively important for understanding the propagation of foreign shocks to the domestic economy.

We begin by documenting that larger French firms are significantly more sensitive to foreign GDP growth. This empirical regularity is prima facie econometric evidence that larger firms are more susceptible to foreign fluctuations. We also show that in our data (i) there is a great deal of heterogeneity in both import and export participation among French firms; and (ii) larger firms are systematically more likely to trade internationally, consistent with a large body of previous literature. These features of the data have the potential to explain the newly documented stylized fact: larger firms' sensitivity to foreign shocks arises from their greater participation in international trade.

The econometric estimates do not lend themselves well to aggregation or to performing counterfactuals. They reveal the differential correlation with foreign GDP across firms, but cannot be used to infer the total impact of a shock on firm growth or the overall GDP change. Thus, we employ a quantitative framework to simulate the effects of foreign shocks on the French economy. The model is calibrated to the observed firm-level information for France, and to the sector-level information for France's trading partners. A distinctive feature of our framework is that it is implemented directly on firm-level data. In other words, objects inside the model are actual firms in 
France. This means that we capture the full extent of the joint heterogeneity across French firms in size, international linkages, and factor shares, without relying on common shortcuts like integrating over assumed parametric underlying productivity distributions. Importantly, our model is solved in general equilibrium with discrete firms, implying that shocks experienced by individual firms can move equilibrium objects such as wages, prices, and GDP. Thus, it is the appropriate environment to quantify the impact of the micro heterogeneity on aggregate outcomes.

The transmission mechanisms in the model are standard. Following a positive foreign productivity shock, firms importing foreign inputs experience a fall in the prices of those inputs, and thus expand production. Changes in foreign demand (which could be due to a foreign productivity shock or a foreign demand shock) affect the firms' export sales. ${ }^{1}$ External shocks are transmitted inside the French economy via domestic input-output linkages and general equilibrium effects on the domestic goods and factor prices. Thus, even purely domestic firms in France are in principle affected by foreign shocks.

The micro result is that foreign shocks are predominantly granular fluctuations. To make this statement precise, consider the response of French GDP to a foreign shock. By definition, this response is a weighted average of individual firms' value added changes following the shock. As in Gabaix (2011) and Gabaix and Koijen (2019), the log GDP change can be decomposed into the simple average value added growth across all firms in France and the covariance between firm size and value added growth, which we call the foreign granular residual. If all firms have the same size or the same response to foreign shocks then the foreign granular residual is zero. If instead the large firms are more responsive to foreign shocks, the foreign granular residual is potentially large.

We quantify the foreign granular residual in two ways. First, we subject our world economy to hypothetical foreign shocks: a $10 \%$ productivity shock to all the countries other than France, and a $10 \%$ foreign demand shock for French goods. Following these shocks, the foreign granular residual is responsible for $45-75 \%$ of the total GDP change, depending on the shock. Second, we simulate the response of the economy to actual foreign productivity shocks, sourced from the Penn World Table. Foreign TFP shocks can account for about one tenth of the actual GDP fluctuations in France. More importantly for us, the standard deviation of the foreign granular residual is $65-70 \%$ of the standard deviation of the fluctuations in French GDP generated by the foreign TFP changes. All in all, both quantitative exercises show that foreign shocks manifest themselves as largely granular fluctuations. ${ }^{2}$

\footnotetext{
${ }^{1}$ Our stylized fact is reduced-form evidence of the relationship between firm size and sensitivity to foreign shocks. In our quantitative model, the sensitivity to foreign shocks arises from import and export links. Our previous work looks directly at the link between firm-level trade and comovement with foreign countries, providing micro evidence for transmission of shocks through trade linkages. Di Giovanni et al. (2014) shows that firms exporting to foreign countries are subject to demand shocks from those countries. Di Giovanni et al. (2018) documents that firms importing from, and exporting to, a foreign country are more correlated with GDP growth in that country. Appendix A.2 connects our reduced-form result to firm-level trade participation.

${ }^{2}$ Various meanings have been attached to the word "granular" in the literature. To be precise, what we mean by
} 
The macro result is that the observed heterogeneity across firms attenuates the impact of foreign shocks. We compare the change in GDP following a foreign shock to the change in GDP in a counterfactual model with identical levels of sectoral trade and output, but no within-sector heterogeneity across firms in importing and exporting. We refer to this alternative as the homogeneous firm model. It is common in international macro and trade, and can be implemented with only sector-level data such as the World Input-Output Database. Following the same foreign shock, the GDP change in the homogeneous firm model is 10-20\% larger than the GDP change in the baseline economy. Surprisingly, the granularity of the economy attenuates the GDP responses to foreign shocks, and thus quantifying the propagation of shocks using models that neglect firm heterogeneity can be misleading. The rest of the paper explores the macro attenuation result and provides the intuition for it.

We connect the micro granularity and the macro attenuation results by exploiting the crosssection of partner countries. In the data, firm-level patterns of trade differ across trading partners. This means that the propagation of country-specific shocks to France depends on which firms trade with that partner. To illustrate this, we shock one foreign country at a time, and record the GDP change and the foreign granular residual in France. The relative importance of the granular residual varies by partner country. At the same time, the macro attenuation effect is stronger for shocks to countries with a larger granular residual. We then show that the relative size of the granular residual is correlated with the size of the firms that trade with that country. Put simply, when trade with a particular country is dominated by especially large French firms, the granular residual is more important, and the attenuation effect is larger. Thus, the micro patterns of trade with individual countries matter for the macro consequences of shocks to those countries, over and above the bilateral trade volumes.

We build intuition for the attenuation effect via a combination of theoretical and numerical results. The baseline model differs from the homogeneous firm model in two respects: (i) heterogeneous firm sales, and (ii) heterogeneous production functions across firms within a sector, reflected in firm-specific imported intermediate input shares. We investigate the consequences of these two sources of heterogeneity in turn. First, we prove analytically that if production functions are identical among firms within a sector, the real GDP change due to a foreign shock is invariant to the

"granular" in this paper is that the foreign granular residual is quantitatively important. More broadly, we use this adjective to capture the notion that foreign shocks produce domestic aggregate fluctuations driven disproportionately by larger firms. It has been understood since Gabaix (2011) that the granular residual can in principle arise from idiosyncratic shocks to large firms, or from a differential response of larger firms to common shocks. While Gabaix (2011) explores the former, this paper emphasizes the latter. A distinct question is whether the observed firm size distribution comes from fat-tailed underlying distributions (what one might term "heterogeneity"), or from idiosyncratic draws that deviate from those underlying distributions (the meaning that Gaubert and Itskhoki (2021) attach to the word "granular"). An advantage of our approach of using actual firms in the quantification is that we never need to take a stand on which of these forces leads to the observed firm data. Our results are invariant to the relative importance of "heterogeneity" vs. "granularity" (in this narrower sense) in the data. 
distribution of market shares across firms. This theoretical result provides a sharp characterization of the source of the attenuation effect: a necessary condition for attenuation is heterogeneity in importing.

We next provide a heuristic illustration for how this dimension of heterogeneity generates attenuation. Raising a firm's imported input share lowers its impact on domestic GDP. This is because mechanically, a higher imported input share means lower demand for domestic value added by the firm. At the same time, raising a firm's imported input share increases its exposure to foreign shocks. Thus, relative to a representative firm world, introducing heterogeneity in imported input shares leads to a negative covariance in the cross section of firms between impact on domestic GDP and exposure to foreign shocks. This negative covariance is the source of the attenuation effect of production function heterogeneity. Because this attenuation effect of firm heterogeneity is to our knowledge new in the literature, we illustrate it using a simple 2-firm model as well as a variation of the full-fledged quantitative model.

We conclude that heterogeneity across firms in the responsiveness to foreign shocks is pervasive at the micro level, and relevant for macro adjustment. Reallocation of market shares towards firms more exposed to imported inputs following a positive foreign shock attenuates the aggregate response of the economy.

Related literature. The paper draws from and contributes to the active literature on the micro origins of aggregate fluctuations. Carvalho (2010) and Acemoglu et al. (2012) modernized the research program on shock propagation through the input networks that dates back to Long and Plosser (1983). A number of papers enriched the theory and quantification of the sectoral input network models (see, among others, Foerster et al., 2011; Acemoglu et al., 2016; Atalay, 2017; Caliendo et al., 2017; Grassi, 2017; Baqaee, 2018; Baqaee and Farhi, 2019a,b; Foerster et al., 2019; Bigio and La'O, 2020). At the same time, the seminal contribution of Gabaix (2011) drew attention to the role of large firms in the macroeconomy, which has been further quantified and formalized by di Giovanni et al. (2014), Carvalho and Grassi (2019), and Gaubert and Itskhoki (2021) among others. Atkeson and Burstein (2008), Eaton et al. (2012), and Burstein et al. (2020) explore the consequences of discreteness in environments with variable markups. The research agendas on input networks and firm granularity are merging, with the latest modeling and measurement exercises capturing network interactions at the firm level (e.g., Barrot and Sauvagnat, 2016; Huneeus, 2018; Lim, 2018; Taschereau-Dumouchel, 2019; Carvalho et al., 2021; Dhyne et al., 2021; Kikkawa et al., 2022; Koenig et al., 2022).

We apply the insights and tools from this literature to the international transmission of shocks. Hummels et al. (2001), Yi (2003), and Johnson and Noguera (2012, 2017) document the importance of international input trade, while Burstein et al. (2008), Bems et al. (2010), Johnson (2014), Eaton 
et al. (2016b), and Eaton et al. (2016a), among others, model and quantify international shock transmission through input trade. Baqaee and Farhi (2019c), Huo et al. (2019), and Kleinman et al. (2020) develop theoretical and quantitative treatments of the international input network model. The international business cycle literature has by and large not used firm-level data in empirical and quantitative assessments of shock transmission. ${ }^{3}$ The few recent exceptions include di Giovanni and Levchenko (2012), Kleinert et al. (2015), Cravino and Levchenko (2017), Blaum et al. (2018), di Giovanni et al. (2018), Blaum (2019), and Boehm et al. (2019). Our paper combines empirics, quantification, and analytical results to highlight the role of different types of heterogeneity. To our knowledge, we are the first to introduce and quantify the foreign granular residual, to document the macro attenuation result, and to show that it is importing rather than exporting heterogeneity that is crucial for attenuation.

\section{The Foreign Granular Residual}

To set the stage for the empirical and quantitative exercises that follow, we set up a simple accounting framework that introduces the concept of the foreign granular residual and illustrates the consequences of heterogeneity for the aggregates. Let $Y_{n}$ denote real GDP in country $n$, and let $Y_{f, n}$ denote the real value added of firm $f$. GDP is just the sum of firm-level value added:

$$
Y_{n}=\sum_{f} Y_{f, n}
$$

We are interested in understanding the change in GDP following some foreign shock. Denote by $d \ln Y_{n}^{F}$ the log change in $n$ 's GDP following that foreign shock, and by $\omega_{f, n,-1} \equiv \frac{Y_{f, n,-1}}{Y_{n,-1}}$ the preshock share of firm $f$ 's value added in total GDP. The aggregate GDP change is the weighted sum of firm-level $\log$ changes $d \ln Y_{f, n}^{F}$ :

$$
d \ln Y_{n}^{F}=\sum_{f} \omega_{f, n,-1} d \ln Y_{f, n}^{F} .
$$

The GDP change can then be written as:

$$
d \ln Y_{n}^{F}=\mathcal{E}^{F}+\Gamma^{F}
$$

where the superscript $F$ on all the values highlights the fact that all of these are changes following a foreign shock. The component $\mathcal{E}^{F} \equiv \frac{1}{N} \sum_{f} d \ln Y_{f, n}^{F}$ is the unweighted average value added change

\footnotetext{
${ }^{3}$ Ghironi and Melitz (2005) and Alessandria and Choi (2007) provide quantitative assessments of the transmission of aggregate shocks using international real business cycle models with heterogeneous firms. In these papers, firm heterogeneity is handled by tracking the moments of the firm size distribution, whereas in our work each actual firm is an object in the model. These papers explore the role of the extensive margin whereas we focus on the intensive margin in the context of heterogeneous export and import participation. The intensive margin is quantitatively more important for aggregate fluctuations and cross-border business cycle comovement in environments with fat-tailed firm-size distributions, as is the case in the data (di Giovanni et al., 2014, 2018).
} 
across all $N$ firms in the economy. The foreign granular residual $\Gamma^{F}$ is the size-weighted firm deviation from the unweighted average, as in Gabaix (2011) and Gabaix and Koijen (2019):

$$
\Gamma^{F} \equiv \sum_{f} \omega_{f, n,-1}\left(d \ln Y_{f, n}^{F}-\frac{1}{N} \sum_{f} d \ln Y_{f, n}^{F}\right) .
$$

To build intuition for the meaning of the granular residual, note that with some manipulation it can be rewritten as a covariance between firm size and the firm value added change:

$$
\Gamma^{F}=\operatorname{Cov}\left(\frac{\omega_{f, n,-1}}{\bar{\omega}}, d \ln Y_{f, n}^{F}\right)
$$

where $\bar{\omega} \equiv \frac{1}{N} \sum_{f} \omega_{f, n,-1}=\frac{1}{N}$. Writing $\Gamma^{F}$ this way helps illustrate the role of granularity in international shock transmission. Since the largest firms are more likely to be internationally connected, we would expect them to have a larger increase in value added following a positive foreign shock, and thus the covariance in (5) to be positive. To observe a quantitatively important $\Gamma^{F}$ requires heterogeneity both in size and in responsiveness to foreign shocks (driven by differences in importing and exporting behavior), and a correlation between the two. Simply put, if firms were heterogeneous in im/exporting, but firm sizes were either homogeneous across firms or uncorrelated with trade participation, $\Gamma^{F}$ would be zero.

From here, we proceed as follows. After introducing the dataset, Section 3 provides reducedform regression evidence that the covariance (5) is positive, by estimating the differential sensitivity of larger firms to foreign GDP growth. Section 4 then sets up a multi-country general equilibrium model of trade that captures this reduced-form pattern through differences across firms in international trade linkages. Section 5 quantifies the size of the foreign granular residual following foreign shocks, and presents the main macro attenuation result. Section 6 concludes.

\section{Data and Basic Facts}

We combine administrative data on the universe of French firms' value added, imports, and exports with standard multi-country sector-level databases of production and trade. The use of micro data for one country allows us to capture the heterogeneous exposure of individual firms to foreign shocks. While such heterogeneity obviously exists in all countries, firm-level information at this level of detail and coverage is not available for multiple countries at once. As a consequence, we will study the impact of firm heterogeneity using the French firm-level data, suppressing heterogeneity within sectors in the rest of the country sample.

\subsection{Firm-Level Variables}

We make use of an administrative dataset that contains balance sheet information collected from individual firms' tax forms, and includes sales, value added, total exports, the cost structure, as 
well as the sector of activity for the universe of French firms over 1995-2007. ${ }^{4}$ This source is complemented with customs data on bilateral export and import flows at the firm level. The resulting dataset is described in greater detail in di Giovanni et al. (2014, 2018). Table A1 reports the distribution of firms across sectors in 2005. Sectors with the largest contribution to aggregate value added are Wholesale, Retail Trade, and Post and Telecommunications. More generally, nontraded sectors are a large share of the French economy, accounting for more than $80 \%$ of firms and $69 \%$ of the value added in our sample. The comparison of these two numbers indicates that nontraded sector firms tend to be relatively small. There are some exceptions, however. For instance, firms in the "Post and Telecommunications" or the "Air Transport" sectors are relatively large.

When describing the variables in this section, we anticipate the notation used in the quantitative framework (Section 4) throughout. Following di Giovanni et al. (2014), we harmonize customs and tax form data to obtain firm-level sales by destination market $\left(X_{f, m n, j}\right.$ for $m=$ France $)$. The tax files contain information on total sales and total exports, which we use to allocate total sales by the firm to the domestic or all foreign markets. We then use customs data to apportion total exports to specific destination markets. We perform a similar exercise for firm inputs. The tax data contain information on total input purchases. We combine it with customs data on the value of imports by origin country and type of product to build values for firm-level source- and sector-specific input expenditures. The customs data do not include trade in services. As a consequence, we have no choice but to treat all services as non-tradables and adjust the calibration accordingly. Appendix A and di Giovanni et al. (2014) provide further detail on apportioning sectors into tradables and nontradables, and the construction of firm-level trade and factor shares.

\subsection{Aggregate and Sectoral Variables}

The main source of data at the country-sector level is the World Input Output Database (WIOD) (Timmer et al., 2015). This dataset combines national input-output tables and data on bilateral trade flows to build the matrix of all intra- and international flows of goods and services between sectors and final consumers. We use the 2013 release of the dataset which covers 40 countries plus a rest of the world aggregate and 35 sectors classified according to the ISIC Revision 3 nomenclature. These data are available over 1995 to 2011 and the benchmark year for the calibration of the quantitative model is 2005 .

The WIOD dataset is used to recover: i) final consumption spending $\left(P_{n} C_{n}\right)$; ii) the value of bilateral sales by sector $\left(X_{m n, j}\right)$; and iii) the sectoral production function parameters, which are used whenever more disaggregated data are not available. We use these data to measure the share of labor in country $n$ sector $j$ 's total costs $\left(\pi_{n, j}^{l}\right)$ as well as the components of the input-output

\footnotetext{
${ }^{4}$ We work with data for this period because after 2011 import data at firm-product level for France are substantially left-censored. Our sample ends in 2007 to sidestep the 2008 trade collapse as well.
} 
matrix, as measured by the share of inputs sourced from country $m$ sector $j$ by firms operating in country $n$ sector $i\left(\pi_{m n, j i}^{M}\right)$. The IO coefficients are readily available from the WIOD. Labor shares are measured by the ratio of value added over output, to be consistent with the interpretation of $L_{n}$ as "equipped labor."

The French administrative data and the WIOD data must be made consistent with each other, as the final dataset must feature firm-level trade flows that aggregate up to the sector-level bilateral trade flows reported in WIOD. In addition, shares of value added in total output implied by the French data must match those implied by WIOD for France. Appendix A describes in detail the harmonization procedure.

\subsection{Basic Facts}

Fact 1: Larger firms are more sensitive to foreign GDP growth. We establish this stylized fact by means of the following heuristic regression:

$$
d \ln Y_{f, n, j, t}=\beta_{0} d \ln Y_{W, t}+\beta_{1} \ln Y_{f, n, j, t-1} \times d \ln Y_{W, t}+\beta_{2} \ln Y_{f, n, j, t-1}+\boldsymbol{\delta}+\epsilon_{f, t},
$$

where $d \ln Y_{f, n, j, t}$ is the $\log$ change in firm value added, $\ln Y_{f, n, j, t-1}$ is its initial log level, $d \ln Y_{W, t}$ is the GDP growth in the world outside of France, and $\boldsymbol{\delta}$ are fixed effects. ${ }^{5}$ The coefficient of interest $\beta_{1}$ captures whether firms of different sizes have differential elasticity of value added growth with respect to foreign GDP.

Table 1 reports the results. The first column presents estimates of (6) without any fixed effects. ${ }^{6}$ Column 2 adds year effects, which implies that we can no longer estimate the main effect of foreign GDP growth. Columns 3-4 include sector $\times$ year effects, implying that the coefficient of interest is estimated from the variation across firms within a sector along the size dimension. The coefficient of interest is strongly positive and significant: larger firms are more sensitive to foreign growth. The point estimate falls when sector $\times$ year effects are added, but remains significant at $1 \%$. It is sizeable in magnitude, implying that a one log point increase in firm size raises the elasticity of firm growth to world GDP growth by about 0.1 .

Next, we check whether larger firms are more sensitive to the foreign business cycle, or simply more procyclical. Column 4 adds an interaction between firm size and French GDP growth. It is clear that larger firms are more sensitive to foreign growth specifically: the interaction term of firm size with respect to the domestic GDP growth is in fact mildly negative. The elasticity with

\footnotetext{
${ }^{5} \mathrm{As}$ is common in firm-level datasets, we do not have firm-specific deflators. Using nominal value added or deflating firm value added by aggregate or sectoral price indices would yield the same result, as we use year and sector-year effects in the estimation.

${ }^{6}$ The main effect of foreign GDP growth is negative. However, the main effect coefficient must be interpreted jointly with the size interaction. Combining the main effect with the size interaction, the impact of foreign growth on firm value added turns positive above $\ln Y_{f, n, j, t}$ of 9 , corresponding to annual value added of about $8 \mathrm{mln}$ euros (the value added variable is in thousands). Note that this main effect coefficient should be interpreted with caution, as this specification does not include any fixed effects and thus omitted factors could be affecting the estimates.
} 
Table 1. Sensitivity to Foreign GDP Growth by Firm Size

\begin{tabular}{|c|c|c|c|c|c|c|}
\hline & \multirow[t]{3}{*}{ (1) } & \multirow[t]{3}{*}{$(2)$} & \multirow[t]{3}{*}{ 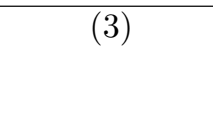 } & \multirow[t]{3}{*}{ (4) } & \multirow{2}{*}{\multicolumn{2}{|c|}{${ }^{(5)}$ Model $^{(6)}$}} \\
\hline & & & & & & \\
\hline & & & & & World & World \\
\hline Dep. Var.: $d \ln Y_{f, n, j, t}$ & \multicolumn{4}{|c|}{ Data } & Prod. & Pref. \\
\hline $\ln Y_{f n i t-1} \times d \ln Y_{W t}$ & $0.173^{a}$ & $0.197^{a}$ & $0.108^{a}$ & $0.131^{a}$ & $0.016^{a}$ & $0.197^{a}$ \\
\hline & $(0.027)$ & $(0.027)$ & $(0.030)$ & $(0.032)$ & $(0.000)$ & $(0.001)$ \\
\hline $\ln Y_{f, n, j, t-1}$ & $-0.019^{a}$ & $-0.019^{a}$ & $-0.019^{a}$ & $-0.019^{a}$ & & \\
\hline & $(0.001)$ & $(0.001)$ & $(0.001)$ & $(0.001)$ & & \\
\hline$d \ln Y_{W, t}$ & $\begin{array}{r}-1.562^{a} \\
(0.171)\end{array}$ & & & & & \\
\hline $\ln Y_{f, n, j, t-1} \times d \ln Y_{F R A, t}$ & & & & $\begin{array}{c}-0.051^{b} \\
(0.022)\end{array}$ & & \\
\hline Observations & $1,518,264$ & $1,518,264$ & $1,518,264$ & $1,518,264$ & 416,651 & 416,651 \\
\hline \# years & 11 & 11 & 11 & 11 & 1 & 1 \\
\hline \# firms & 138,024 & 138,024 & 138,024 & 138,024 & 416,651 & 416,651 \\
\hline Adjusted $R^{2}$ & 0.005 & 0.012 & 0.019 & 0.019 & 0.349 & 0.287 \\
\hline Fixed Effects & - & Year & Sector $\times$ Year & Sector $\times$ Year & Sector & Sector \\
\hline
\end{tabular}

Notes: This table reports the estimates of Equation (6). Standard errors clustered at the firm level in parentheses with ${ }^{a},{ }^{b}$ and ${ }^{c}$ denoting coefficients significantly different from zero at the 1,5 and $10 \%$ levels, respectively. $d \ln Y_{F R A, t}$ denotes French GDP growth.

respect to foreign growth is if anything higher when we control for the domestic growth interaction term. ${ }^{7}$

Fact 2: Larger firms are more likely to both export and import. Figure 1(a) plots the cumulative distribution function of firm-level share of exports in total sales. Similarly, Figure 1(b) plots the distribution of the intensity of imported input use, summarized by the share of foreign inputs in firms' total input expenditure $\left(\sum_{n \neq m} \sum_{i \in T} \pi_{f, m n, i j}^{M}\right)$. In both plots, the solid (red) line depicts the unweighted distribution and the (blue) circles the distribution weighted by the firms' share in overall value added.

We stress two features of these figures, both of which are known in the trade literature and are confirmed in our data. First, there is a great deal of heterogeneity across firms in both export intensity and imported input use. Overall, $69 \%$ of the firms producing tradable goods do not export

\footnotetext{
${ }^{7}$ We also implemented a specification with firm fixed effects. The interaction coefficient of interest is still highly statistically significant and if anything larger in magnitude than the coefficients in Table 1 . We do not focus on this specification because firm fixed effects change the substantive interpretation of both the size main effect and the size-foreign growth interaction. The interaction term with the size variable now captures whether firms that did unusually well last period relative to the firm-specific mean are more susceptible to foreign growth. Thus, the coefficient now reflects a within- rather than a cross-firm comparison. Since both our substantive story and the model quantification are based on the cross-sectional differences between firms in size and susceptibility to foreign shocks, the specification without firm effects exploits the variation in the data that corresponds more closely to the theory and quantification.
} 
Figure 1. Distributions of Export and Imported Input Use Intensities Across French Firms

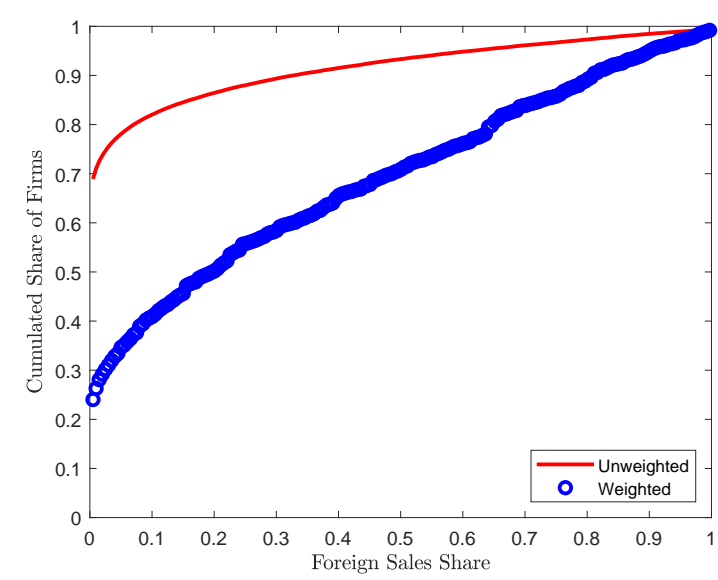

(a) Export Intensity

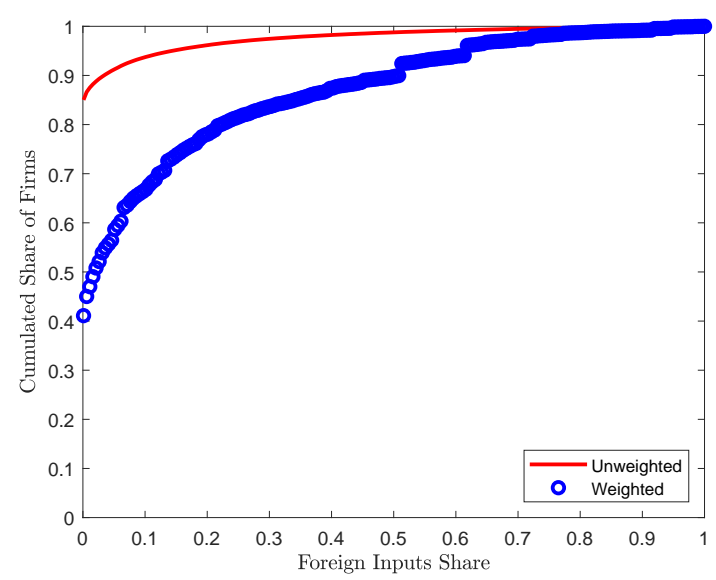

(b) Imported Input Use Intensity

Notes: The left panel plots the cumulative distribution of firms according to their degree of exporting intensity, defined by the share of their sales going to foreign markets. The right panel plots the cumulative distribution of firms according to their share of inputs coming from other countries in total input spending. The solid (red) lines correspond to the unweighted distributions and the (blue) circles to the weighted distributions, where firms' weights are defined according to their share in the aggregate value added. The left panel is restricted to firms in the tradable sectors. Source: French customs and balance sheet data for 2005 .

in our data. Among the firms that do export, many have sales that are strongly biased towards the domestic market. Still, about $7 \%$ of firms exhibit a share of exports in total sales of above $50 \%$, and are thus quite exposed to foreign demand shocks. Similarly, more than $85 \%$ of firms source the entirety of their inputs locally, thus isolating themselves from (direct) foreign input price shocks. At the other end of the spectrum, about $2 \%$ of firms source more than $40 \%$ of their inputs from abroad.

Second, participation in foreign markets is heavily tilted towards larger firms. This is illustrated in Figure 1 by the comparison between the weighted and unweighted distributions. In both cases, the cdfs of the weighted distributions are substantially below the unweighted ones, meaning that on average larger firms have higher export and import intensities. For instance, the $7 \%$ of firms with more than $50 \%$ of their sales going abroad represent as much as $29 \%$ of the overall value added in the tradable sector. On the import side, the $15 \%$ of firms that source some inputs from abroad account for nearly $60 \%$ of aggregate value added, and firms sourcing more than $40 \%$ of their inputs abroad account for $13 \%$ of aggregate value added. In unreported results, we checked that the heterogeneity is not driven by cross-sector differences in overall exposure. While non-traded good sectors tend to be relatively less dependent on foreign inputs, most of the heterogeneity is actually driven by the within-sector variation. 
Discussion. The foreign granular residual is the covariance between firm size and firm-level responses to foreign shocks. Thus, our Fact 1 regressions are the most direct reduced-form way to get at the object encapsulated by (5). As noted in Section 2, both heterogeneities - in size and in responsiveness to foreign shocks - as well as a positive correlation between them are required for the foreign granular residual to be quantitatively important. The following section models and quantifies the propagation of foreign shocks to the French economy in an environment with firms heterogeneous in both size and trade participation. Our theoretical framework rationalizes the greater responsiveness of larger firms to foreign shocks through the combination of (i) Fact 2; and (ii) the transmission of foreign shocks through international trade linkages. To give a partial review of the existing body of supporting evidence on (ii), di Giovanni and Levchenko (2010) shows that international trade synchronizes sectoral output across countries if those sectors use each other as intermediate inputs. Di Giovanni et al. (2014) shows that firms exporting to foreign countries are subject to demand shocks from those countries. Di Giovanni et al. (2018) provides econometric evidence that firms importing from, and exporting to, a foreign country are more correlated with GDP growth in that country. The latter two papers use the same French micro data as in this paper. Boehm et al. (2019) demonstrates that US firms that imported inputs subject to an exogenous shock (the 2011 Tohoku earthquake) contracted their output dramatically. To avoid redundance, we do not revisit these types of exercises in the main text. Appendix A.2 further explores Fact 1 by implementing several alternative specifications and connecting it to the international trade participation at the firm level.

While to our knowledge we are the first to document the differential sensitivity of larger firms to foreign GDP growth, qualitatively one could have inferred Fact 1 by putting together Fact 2 and the existing evidence that firm-level trade linkages transmit shocks internationally. Our paper's main contribution is to build on Fact 1 in two ways. First, we introduce and quantify a simple and intuitive statistic that captures this notion: the foreign granular residual. This is valuable because import and export relationships are complex and heterogeneous across sources, destinations, sectors, and firms. The foreign granular residual is easy to compute and summarizes the impact of all of these heterogeneities in a single number. Moreover, while we could have deduced from existing knowledge that the foreign granular residual exists, we did not know its magnitude.

Second, and perhaps more importantly, we uncover the attenuation effect of firm heterogeneity on the response of domestic GDP to a foreign shock. To our knowledge, this attenuation effect is new to the literature. In contrast to the more data-driven previous work by ourselves and others, documenting the attenuation effect requires a general equilibrium framework, which we provide in this paper. The attenuation effect is surprising, as partial equilibrium thinking would if anything lead one to expect an amplification effect of heterogeneity. Finally, we provide a sharp characterization of which heterogeneity matters for the attenuation effect: importing. The 
majority of the heterogeneous firm trade literature has focused on the heterogeneity in exporting. By contrast, we show that it is the importing heterogeneity that has the aggregate implications when it comes to cross-border shock transmission.

\section{Quantitative Framework}

This section builds a heterogeneous-firm, multi-country, multi-sector model of trade. Within a sector, the production structure is a variant of Melitz (2003) and Chaney (2008) with a fixed number of firms. Crucially, we allow for heterogeneity in both input linkages and destinationspecific sales at the firm level. The model features endogenous factor supply so that we can analyze how domestic and foreign shocks are transmitted to GDP fluctuations.

\subsection{Setup}

The world is comprised of $\mathcal{M}$ countries and $\mathcal{J}$ sectors. Countries are indexed by $m$, $n$, and $k$, sectors by $i$ and $j$, and firms by $f$ and $g$. Countries trade both intermediate and final goods. The notation follows the convention that the first subscript always denotes the exporting (source) country, and the second subscript the importing (destination) country.

Households. There are $\bar{L}_{n}$ households in country $n$. Each one consumes goods and supplies labor. Preferences over consumption and leisure are GHH (Greenwood et al., 1988):

$$
U\left(c_{n}, l_{n}\right)=\nu\left(c_{n}-\frac{\psi_{0}}{\bar{\psi}} l_{n}^{\bar{\psi}}\right)
$$

where $c_{n}$ is per-capita consumption, $l_{n}$ the per-capita labor supply, and the function $\nu$ is increasing and concave. Note that the $l_{n}$ should be thought of as "equipped labor" (Alvarez and Lucas, 2007), and thus captures the supply of all the primary factors. ${ }^{8}$

The final consumption aggregate is Cobb-Douglas in the $j$ sectors, with expenditure shares $\vartheta_{n, j}$ :

$$
c_{n}=\prod_{j} c_{n, j}^{\vartheta_{n, j}},
$$

\footnotetext{
${ }^{8}$ We do not include capital explicitly as a production factor, and do not endogenize it through capital accumulation. The quantitative analysis restricts attention to the within-period effect of a foreign shock on domestic GDP. It is common to assume a time-to-build lag for capital, such that investment does not result in a higher capital stock in the same period when it is made. Thus a change in investment has no impact on within-period productive capacity of the economy, and we can safely ignore it when analyzing the contemporaneous effect of the foreign shock on output. Allowing for the possibility of investment may still affect agents' intertemporal substitution decisions. Here, there are two things to note. First, the GHH preferences imply a purely static labor supply curve and feature zero wealth effect on the labor supply. So the future state variables, such as future capital stocks, would not affect the labor supply decision even if we added dynamics and investment. Second, our object of analysis is GDP and not consumption. Adding intertemporal tradeoffs may affect within-period consumption, but not GDP as it is a function of productivity and the (equipped) labor input, whose supply decision is static. Indeed, in a framework very similar to ours, Huo et al. (2019) show that the response of GDP in a static model (with fixed capital) coincides with the within-period response in the fully dynamic DSGE model with a one-period time-to-build lag for capital. Thus adding dynamics and delayed responses to shocks would not change the answer for what is the within-period change in GDP, which is the object of our quantification.
} 
where $c_{n, j}$ is the per capita final consumption of sector $j$. Therefore, the ideal consumption price index is:

$$
P_{n}=\prod_{j}\left(\frac{P_{n, j}}{\vartheta_{n, j}}\right)^{\vartheta_{n, j}}
$$

where $P_{n, j}$ is the price index of sector $j$ goods in country $n$. Straightforward steps lead to the following labor supply:

$$
L_{n}=\left(\frac{1}{\psi_{0}} \frac{w_{n}}{P_{n}}\right)^{\frac{1}{\psi-1}} \bar{L}_{n}
$$

where $w_{n}$ is the price of equipped labor in country $n$.

Denote by $C_{n} \equiv c_{n} \bar{L}_{n}$ the aggregate final consumption in country $n$, and let $C_{n, j} \equiv c_{n, j} \bar{L}_{n}$ be the aggregate final consumption of sector $j$. Each sector's consumption is an Armington aggregate of origin-specific components:

$$
C_{n, j}=\left[\sum_{m} \mu_{m n, j}^{\frac{1}{\sigma}} C_{m n, j} \frac{\sigma-1}{\sigma}\right]^{\frac{\sigma}{\sigma-1}}
$$

where $C_{m n, j}$ is final consumption in country $n$ of sector $j$ imports from country $m$. Then the price index for sector $j$ consumption in country $n$ is:

$$
P_{n, j}=\left[\sum_{m} \mu_{m n, j} P_{m n, j}^{1-\sigma}\right]^{\frac{1}{1-\sigma}}
$$

where $P_{m n, j}$ is the price index for exports from $m$ to $n$ in sector $j$, defined below. Final demand for goods from $m$ is:

$$
P_{m n, j} C_{m n, j}=\frac{\mu_{m n, j} P_{m n, j}^{1-\sigma}}{P_{n, j}^{1-\sigma}} P_{n, j} C_{n, j}=\frac{\mu_{m n, j} P_{m n, j}^{1-\sigma}}{P_{n, j}^{1-\sigma}} \vartheta_{n, j} P_{n} C_{n} .
$$

Denote by $\Pi_{n}$ the aggregate profits of firms owned by households in $n$, and by $D_{n}$ any trade imbalance. Then the final expenditure in $n$ on goods coming from country $m$ sector $j$ is:

$$
P_{m n, j} C_{m n, j}=\frac{\mu_{m n, j} P_{m n, j}^{1-\sigma_{j}}}{P_{n, j}^{1-\sigma_{j}}} \vartheta_{n, j}\left[w_{n}\left(\frac{1}{\psi_{0}} \frac{w_{n}}{P_{n}}\right)^{\frac{1}{\psi-1}} \bar{L}_{n}+\Pi_{n}+D_{n}\right] .
$$

Note that we use the French customs data for imports at the firm level, and thus every import transaction is associated with a French firm (which may be a wholesaler or a retailer). Thus, French final consumers are never observed to import final consumption goods directly, and as a result French final consumption is composed only of domestically-supplied final goods. ${ }^{9}$ For all the other countries, we do not have firm-level data on imports, but instead have final consumption data by source country from WIOD. Thus, we assume that foreign consumers import final goods directly.

\footnotetext{
${ }^{9}$ Formally, when $n=$ France, $\mu_{m n, j}=0 \forall m \neq n, P_{n, j}=P_{n n, j}$, and $P_{n n, j} C_{n n, j}=P_{n, j} C_{n, j}=$ $\vartheta_{n, j}\left[w_{n}\left(\frac{1}{\psi_{0}} \frac{w_{n}}{P_{n}}\right)^{\frac{1}{\psi-1}} \bar{L}_{n}+\Pi_{n}+D_{n}\right]$, where $P_{n n, j}$ is the ideal price index of output produced by French firms in France.
} 
Sectors. Sectors are populated by heterogeneous monopolistically-competitive firms. Not all firms sell to all destinations. Denote by $\Omega_{m n, j}$ the set of firms from country $m$, sector $j$ that sell to country $n$. The CES aggregate of output in sector $j$ of firms from $m$ selling in country $n$ is:

$$
Q_{m n, j}=\left[\sum_{f \in \Omega_{m n, j}} \xi_{f, m n, j}^{\frac{1}{\rho}} Q_{f, m n, j}^{\frac{\rho-1}{\rho}}\right]^{\frac{\rho}{\rho-1}}
$$

where $Q_{f, m n, j}$ is the quantity sold to country $n$ by firm $f$ from country $m$ and sector $j .{ }^{10}$ The taste shock to a firm's destination-specific sales $\xi_{f, m n, j}$ is at this point left unrestricted. It could be allowed to have a firm-specific global component, and/or a source-destination-sector common component across firms. The latter would be isomorphic to $\mu_{m n, j}$ in the cross section. The price level of the country $m$, sector $j$ aggregate in destination $n$ is:

$$
P_{m n, j}=\left[\sum_{f \in \Omega_{m n, j}} \xi_{f, m n, j} p_{f, m n, j}^{1-\rho}\right]^{\frac{1}{1-\rho}},
$$

where $p_{f, m n, j}$ is the price charged by firm $f$ in country $n$.

Let $X$ denote expenditure (at each level of aggregation). Then demand faced by firm $f$ in country $n$ is:

$$
X_{f, m n, j}=\xi_{f, m n, j}\left(\frac{p_{f, m n, j}}{P_{m n, j}}\right)^{1-\rho} X_{m n, j} .
$$

Thus, $X_{m n, j}$ is the total value of exports from $m$ to $n$ in sector $j$, and $X_{f, m n, j}$ is the value of exports by firm $f$.

Firms. Firms face downward-sloping demand and set price equal to a constant markup $\frac{\rho}{\rho-1}$ over the marginal cost. (Below we show that the results are robust to allowing variable markups à la Atkeson and Burstein (2008), such that larger firms have both higher and more flexible markups.) Firms located in $m$ face an iceberg cost of $\tau_{m n, j}$ to export to $n$. They have a total factor productivity $a_{f}$, and the cost of the input bundle

$$
b_{f, m, j}=\left[\alpha_{f, m, j} w_{m}^{1-\phi}+\left(1-\alpha_{f, m, j}\right)\left(P_{f, m, j}^{M}\right)^{1-\phi}\right]^{\frac{1}{1-\phi}},
$$

where $\alpha_{f, m, j}$ is a firm-specific parameter governing the firm's labor share. The cost of intermediate inputs $P_{f, m, j}^{M}$ is firm-specific, and given by:

$$
P_{f, m, j}^{M}=\left[\sum_{i} \sum_{k} \gamma_{f, k m, i j} P_{k m, i}^{1-\eta}\right]^{\frac{1}{1-\eta}},
$$

\footnotetext{
${ }^{10}$ In the counterfactual experiments below, we assume that following a foreign shock, the sets of firms serving each market $\Omega_{m n, j}$ are unchanged. See di Giovanni et al. $(2014,2018)$ for evidence that the extensive margin adjustments are not quantitatively important at the business cycle frequency.
} 
where $\gamma_{f, k m, i j}$ is the parameter governing the use of inputs sourced from country $k$ sector $i$ by firm $f$ operating in country $m$, sector $j$. That is, firms in $m$ use inputs from potentially all countries $k$ in each sector $i$, with firm-specific taste shifters $\gamma_{f, k m, i j}$. Some of these will be zero, i.e. the firm does not use inputs from a particular sector and country. Sales by firm $f$ from country $m$ in destination $n$ are

$$
X_{f, m n, j}=\xi_{f, m n, j}\left(\frac{\frac{\rho}{\rho-1} \frac{\tau_{m n, j} b_{f, m, j}}{a_{f}}}{P_{m n, j}}\right)^{1-\rho} X_{m n, j} .
$$

Equilibrium. Market clearing for exports from $m$ to $n$ in sector $j$ is:

$$
\begin{aligned}
X_{m n, j}= & \frac{\mu_{m n, j} P_{m n, j}^{1-\sigma}}{P_{n, j}^{1-\sigma}} \vartheta_{n, j}\left[w_{n}\left(\frac{1}{\psi_{0}} \frac{w_{n}}{P_{n}}\right)^{\frac{1}{\psi}-1} \bar{L}_{n}+\Pi_{n}+D_{n}\right] \\
& +\sum_{i} \sum_{f \in i} \frac{\rho-1}{\rho}\left(1-\pi_{f, n, i}^{l}\right) \pi_{f, m n, j i}^{M} \sum_{k} \xi_{f, n k, i}\left(\frac{\frac{\rho}{\rho-1} \frac{\tau_{n k, i} b_{f, n, i}}{a_{f}}}{P_{n k, i}}\right)^{1-\rho} X_{n k, i},
\end{aligned}
$$

where $\pi_{f, m, j}^{l}$ and $\pi_{f, k m, i j}^{M}$ are firm $f$ 's expenditure shares on labor and input from sector $i$, country $k$, respectively:

$$
\begin{gathered}
\pi_{f, m, j}^{l}=\frac{\alpha_{f, m, j} w_{m}^{1-\phi}}{\alpha_{f, m, j} w_{m}^{1-\phi}+\left(1-\alpha_{f, m, j}\right)\left(P_{f, m, j}^{M}\right)^{1-\phi}} \\
\pi_{f, k m, i j}^{M}=\frac{\gamma_{f, k m, i j} P_{k m, i}^{1-\eta}}{\sum_{i} \sum_{n} \gamma_{f, n m, i j} P_{n m, i}^{1-\eta}} .
\end{gathered}
$$

In Equation (10), the first line is the final demand, and the second is the intermediate demand. Note that the intermediate demand is a summation of firm-level intermediate demands, and thus captures the notion that not all firms, even within the same sector, will import inputs from a particular foreign sector-country with the same intensity. The price indices are:

$$
P_{m n, j}=\left[\sum_{f \in \Omega_{m n, j}} \xi_{f, m n, j}\left(\frac{\rho}{\rho-1} \frac{\tau_{m n, j} b_{f, m, j}}{a_{f}}\right)^{1-\rho}\right]^{\frac{1}{1-\rho}} .
$$

Total labor compensation in the sector is the sum of firm-level expenditures on labor:

$$
\begin{aligned}
w_{n} L_{n, j} & =\frac{\rho-1}{\rho} \sum_{f \in j} \pi_{f, n, j}^{l} \sum_{k} X_{f, n k, j} \\
& =\frac{\rho-1}{\rho} \sum_{f \in j} \pi_{f, n, j}^{l} \sum_{k} \xi_{f, n k, j}\left(\frac{\frac{\rho}{\rho-1} \frac{\tau_{n k, j} b_{f, n, j}}{a_{f}}}{P_{n k, j}}\right)^{1-\rho} X_{n k, j} .
\end{aligned}
$$


Labor market clearing ensures that real wages adjust to equate the aggregate labor demand (righthand side) with labor supply:

$$
\begin{aligned}
\left(\frac{1}{\psi_{0}} \frac{w_{n}}{P_{n}}\right)^{\frac{1}{\psi-1}} \bar{L}_{n} & =\sum_{j} L_{n, j} \\
& =\frac{\rho-1}{\rho} \frac{1}{w_{n}} \sum_{j} \sum_{f \in j} \pi_{f, n, i}^{l} \sum_{k} \xi_{f, n k, j}\left(\frac{\frac{\rho}{\rho-1} \frac{\tau_{n k, j} b_{f, n, j}}{a_{f}}}{P_{n k, j}}\right)^{1-\rho} X_{n k, j} .
\end{aligned}
$$

The system of equations (10), (11), and (12) defines equilibrium wages, prices, and expenditures.

Heterogeneity. In the cross-section, heterogeneity in firm size is thus driven by productivity, taste/quality, labor share, and input sourcing differences across firms. To illustrate, the share of firm $f$ 's sales in total sales by domestic firms to the home market in sector $j$ is:

$$
\pi_{f, n n, j}=\frac{\xi_{f, n n, j} a_{f}^{\rho-1}\left[\alpha_{f, n, j} w_{n}^{1-\phi}+\left(1-\alpha_{f, n, j}\right)\left(P_{f, n, j}^{M}\right)^{1-\phi}\right]^{\frac{1-\rho}{1-\phi}}}{\sum_{g \in \Omega_{n n, j}} \xi_{g, n n, j} a_{g}^{\rho-1}\left[\alpha_{g, n, j} w_{n}^{1-\phi}+\left(1-\alpha_{g, n, j}\right)\left(P_{g, n, j}^{M}\right)^{1-\phi}\right]^{\frac{1-\rho}{1-\phi}}} .
$$

Sales dispersion across firms in the same market is generated by differences in productivity $a_{f}$, the taste shifter $\xi_{f, n n, j}$, and input sourcing shifters $\gamma_{f, k n, i j}$ (even though we assume that all firms face the same input prices $\left.P_{k n, i}\right) .{ }^{11}$ As will become clear below, we will not need to take a stand on the levels of $a_{f}, \xi_{f, n n, j}$, and $\gamma_{f, k n, i j}$. Instead the counterfactual exercises will use the observed shares such as $\pi_{f, n m, j}$ directly to calibrate the model at the baseline period and then use the equilibrium conditions to compute the changes in those $\pi_{f, n m, j}$ 's between the baseline and the counterfactual equilibrium.

Following a shock, what are the reasons that firms will differ in their value added growth rates $d \ln Y_{f, n}^{F}$ ? To first order we can write the log change in value added of firm $f$ as:

$$
\begin{aligned}
d \ln Y_{f, n}^{F} \approx & (1-\rho)\left[\pi_{f, n, j,-1}^{l} d \ln w_{n}+\sum_{i} \sum_{k}\left(1-\pi_{f, n, j,-1}^{l}\right) \pi_{f, k n, i j,-1}^{M} d \ln P_{k n, i}\right] \\
& +\sum_{m} s_{f, n m, j,-1} d \ln \left[\xi_{f, n m, j}\left(\frac{\tau_{n m, j}}{P_{n m, j}}\right)^{1-\rho} X_{n m, j}\right],
\end{aligned}
$$

where $s_{f, n m, j,-1}$ is the pre-shock share of market $m$ in the total gross sales of firm $f$. Thus, a firm that only serves the domestic market has $s_{f, n n, j,-1}=1$ and $s_{f, n m, j,-1}=0 \forall m \neq n$.

\footnotetext{
${ }^{11}$ It may be that an additional difference between large and small firms is in the returns to scale. We could not find studies that estimate production elasticities/returns to scale that vary by firm size within a sector. We suspect that part of the reason this has not yet been done is that such an exercise would face the challenge that we usually do not observe prices and quantities separately at the firm level. As a result, any regression of firm revenues (deflated by the sectoral price index) on inputs is subject to the criticism that the resulting estimates are revenue elasticities and not output elasticities. The variation in revenue elasticities is equally consistent with either differences in production parameters (e.g., returns to scale) or with differences in demand parameters (e.g., markups, demand elasticities).
} 
The first line in (13) captures the change in the firm's costs, and the second line the change in the firm's demand following any external shock. Equation (13) highlights the sources of differential responses. On the cost side, following a shock in country $k$, only firms that import from $k-$ $\pi_{f, k n, i j}^{M} \neq 0$ - directly experience a change in input costs. At the same time, the change in foreign demand - be it from the price-adjusted foreign expenditure $X_{n m, j} / P_{n m j}^{1-\rho}$, or from a taste $\left(\xi_{f, n m, j}\right)$ or trade cost shock - will to first order affect only firms that export to country $m$, and even among those firms will vary with the sales share to that market.

At the same time, this expression underscores the general-equilibrium channels that will operate and thus should be accounted for. To the extent that the foreign shock changes domestic wages $\left(d \ln w_{n}\right)$, all firms in $n$ will be affected in proportion to their labor share. Also, all firms sell domestically. Thus, if the foreign shock affects domestic demand $d \ln \left(X_{n n, j} / P_{n n, j}^{1-\rho}\right)$, it will reach all firms in $n$. Finally, even the non-importing firms' input prices $d \ln P_{n n, i}$ change through secondorder input linkages and general equilibrium effects.

It is ultimately an empirical and quantitative question how much $d \ln Y_{f, n}^{F}$ varies across firms, and how it covaries with firm size. Section 3.2 provides econometric evidence that $d \ln Y_{f, n}^{F}$ is indeed heterogeneous in its comovement with foreign GDP. The reduced-form results are however silent on the relative importance of the direct effects on the connected firms and the general equilibrium effects on all firms in the economy. The quantitative analysis addresses this question.

GDP accounting in the model. GDP is real value added. Following the national accounting conventions, in the main text we report the results for real GDP obtained using the double-deflation procedure. ${ }^{12}$ This definition of real GDP corresponds to the notion of the change in the physical final output produced by the economy. The procedure for computing real GDP implicitly defines the GDP deflator, which we take to be the measure of the aggregate price level change. The GDP deflator is required to compute real value added changes for individual firms following a shock. Thus, in implementing the decomposition (3), we deflate each firm's nominal value added growth with the GDP deflator. This procedure ensures that aggregate real GDP is the sum of all firms' real value added. Appendix B.1 presents the complete set of definitions and formulas underlying the construction of the real GDP and the GDP deflator, which mimic the national accounts procedures.

As an alternative, we can deflate nominal GDP change by the CPI $\left(P_{n}\right.$ in Equation $\left.(7)\right)$. The CPI-deflated GDP incorporates changes in prices of imported goods following a foreign shock. This notion of real GDP corresponds to the change in the real purchasing power of a country's final output from the perspective of the consumer. Thus, this concept of real GDP will increase following a reduction in import prices even if the physical quantities of every good produced by the economy were unchanged. Table A5 reports the main results for CPI-deflated real GDP.

\footnotetext{
${ }^{12}$ See also Kehoe and Ruhl (2008), Burstein and Cravino (2015), and Huo et al. (2019).
} 


\subsection{Calibration}

To perform counterfactuals that simulate the impact of foreign shocks on domestic firms and the aggregate economy, we follow the approach of Dekle et al. (2008) and express the equilibrium conditions in terms of gross changes in endogenous variables, to be solved for as a function of the shocks expressed in gross changes and the initial (pre-shock) observables. Appendix B.2 describes the procedure in detail.

Importantly, each actual firm in France is an object inside the model, and the solution is implemented directly on the observed firm-level data for France. Doing so requires data on firm-destination-specific sales shares $\pi_{f, n k, j}$, firm-source-specific sectoral input expenditure shares $\pi_{f, m n, j i}^{M}$, as well a firm-specific primary factor shares $\pi_{f, n, i}^{l}$. We only have this information for France, and thus for the other countries the model collapses to the standard international trade model with sector-level input-output linkages (see, e.g. the Handbook chapter by Costinot and Rodríguez-Clare, 2014). For the other countries we use WIOD to obtain sector-level counterparts of these shares. For French firms, $\pi_{f, m n, j i}^{M}$ 's are available for imported inputs, but not domestic ones. The domestic input-output linkages are inferred using firm-level data on overall input usage and sector-level information on domestic IO linkages. See Section 3 and Appendix A for details on the construction of all firm- and sector-specific shares.

In addition to the initial-period values taken from the data, solving the model requires a small number of structural parameters. Table 2 summarizes the calibration. We set the elasticity of substitution between firms in the same sector selling to the same destination to $\rho=3$, a common value according to standard estimates (see e.g. Broda and Weinstein, 2006). We set the Armington elasticity of substitution between goods coming from different source countries to $\sigma=1.5$. This is the value favored by the international business cycle literature following Backus et al. (1995), and is supported by the recent estimates by Feenstra et al. (2018). We set the labor supply parameter to $\bar{\psi}=3$, implying a Frisch labor supply elasticity of 0.5, as advocated by Chetty et al. (2013). ${ }^{13}$ In the baseline, we set the production function elasticities $\eta=\phi=1$ (Cobb-Douglas), as is standard in the literature. The robustness analysis implements both higher and lower values of each of these parameters.

\footnotetext{
${ }^{13}$ While econometric estimates are typically for the labor supply elasticity, in our model the primary factor is interpreted as equipped labor, i.e. a capital-labor composite. Huo et al. (2020) provide a formulation in which withinperiod supply of capital is also upward-sloping due to the utilization margin. In their formulation, the equipped labor supply curve is still isoelastic in the real wage, but with a different exponent than the pure labor supply. Whether the elasticity of the equipped labor supply is higher or lower than the pure labor supply elasticity depends on the relative curvatures of utility with respect to labor input vs. capital utilization. Huo et al. (2020)'s preferred calibration leads to the composite labor-capital bundle supply elasticity in the real wage virtually identical to what we adopt here for the equipped labor supply elasticity. (Details available upon request.) More broadly, Huo et al. (2020) describe the conditions under which adding a capital margin leads to a formulation of the equipped labor supply with the same functional form as in the main text, but a potentially different value of the equipped labor supply elasticity. Thus, uncertainty over this parameter can be covered by performing sensitivity checks on it, as we do in Appendix Tables A6, A7, and A8.
} 
Table 2. Parameter Values

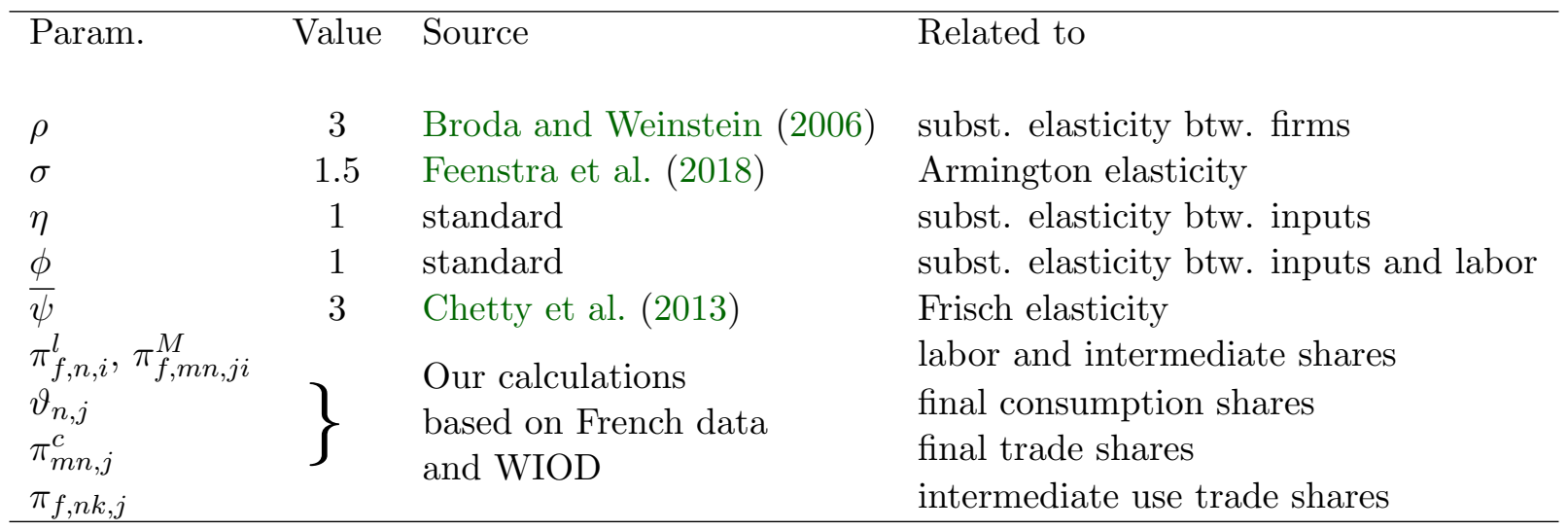

Notes: This table summarizes the parameter values used in the calibration.

Our model does not feature endogenous deficits. In all our experiments, we thus assume that the change in deficits is zero: $\widehat{D}_{n}=0$. We adopt a similar approach to profits: $\widehat{\Pi}_{n}=0$. In the absence of assumptions on multinational production and ownership of firms, in an open economy like France changes in profits are not pinned down in our framework. This is because the aggregate profits in Equation (10) refer to those used by French residents for domestic consumption spending. These are not the same as the profits of firms operating in France, both because French residents own French multinationals operating abroad and thus have claims on those foreign-generated profits, and because not all firms operating in France are domestically-owned, and the profits of foreign multinational affiliates operating in France are not available to French residents for consumption spending. Since the profit share of GDP is under 10\%, and for our counterfactuals what matters is not the level of the profit share but the change, as an approximation we abstract from the impact of changes in profits on final consumption in our counterfactuals. Sections 5.1-5.2 check robustness to an alternative specification of the profit change.

\section{Quantitative Results}

\subsection{Micro: the Granular Origins of International Shock Transmission}

We start by simulating the impact on the French economy of a $10 \%$ productivity improvement in every foreign country in the sample. The left panel of Table 3 presents the results of the decomposition (3). As discussed above, we report the real GDP changes deflated by the GDP deflator. French GDP increases by $2.8 \%$ following a $10 \%$ world productivity shock. This is a sizeable GDP change considering that France itself does not experience the productivity shock, and thus the entire effect is due to it being transmitted to France via goods trade linkages. 
Table 3. Responses of French Real GDP to 10\% Foreign Productivity and Demand Shocks

\begin{tabular}{|c|c|c|c|c|c|c|}
\hline & $d \ln Y^{F}$ & $\mathcal{E}^{F}$ & $\Gamma^{F}$ & $d \ln Y^{F}$ & $\mathcal{E}^{F}$ & $\Gamma^{F}$ \\
\hline Shock: & \multicolumn{3}{|c|}{ Productivity } & \multicolumn{3}{|c|}{ Demand } \\
\hline $\begin{array}{c}\text { Baseline } \\
\text { Share: }\end{array}$ & 2.77 & $\begin{array}{l}0.70 \\
0.253\end{array}$ & $\begin{array}{l}2.07 \\
0.747\end{array}$ & 0.35 & $\begin{array}{l}0.19 \\
0.533\end{array}$ & $\begin{array}{l}0.16 \\
0.468\end{array}$ \\
\hline $\begin{array}{l}\text { Homogeneous firms } \\
\text { Share: }\end{array}$ & 3.39 & $\begin{array}{l}3.36 \\
0.991\end{array}$ & $\begin{array}{l}0.03 \\
0.009\end{array}$ & 0.38 & $\begin{array}{l}0.37 \\
0.957\end{array}$ & $\begin{array}{l}0.01 \\
0.043\end{array}$ \\
\hline
\end{tabular}

Sector-Level Decomposition

$\begin{array}{ccccccc} & d \ln Y^{F} & \mathcal{E}_{\mathcal{J}}^{F} & \Gamma_{\mathcal{J}}^{F} & d \ln Y^{F} & \mathcal{E}_{\mathcal{J}}^{F} & \Gamma_{\mathcal{J}}^{F} \\ \text { Baseline } & 2.77 & 2.13 & 0.64 & 0.35 & 0.60 & -0.25 \\ \text { Share: } & & 0.770 & 0.230 & & 1.702 & -0.702\end{array}$

Notes: This table reports the change in French GDP, in percentage points, following a 10\% productivity shock (left panel) or a $10 \%$ foreign demand shock for French goods (right panel) in every other country in the world, in both the baseline model and the alternative model that suppresses firm heterogeneity. The table reports the decomposition of the GDP change into the unweighted average and granular residual terms as in (3).

Our central micro result concerns not so much the overall magnitude, but the role of heterogeneity. Decomposing the aggregate elasticity into the unweighted mean and the granular residual, we find that the latter is positive as expected and quite large. The $\Gamma^{F}$ term is responsible for $75 \%$ of the overall effect of this shock. Thus, there is a quantitatively large role of the heterogeneity in firm-level international linkages in the business cycle transmission across countries.

To illustrate the main result, Figure 2(a) plots the histogram of firm-level value added changes in the baseline model for the world productivity shock. The dispersion in firm-level growth rates is evident. While most firm value added changes are positive, there is substantial density below zero as well - some firms shrink in response to a positive shock in the rest of the world. At the same time, there is an upper tail, as the density of $d \ln Y_{f, n}^{F}$ above 10 percentage points change is visible. Figure 2(b) displays a binscatter of the average $d \ln Y_{f, n}^{F}$ for firms of different sizes $\omega_{f, n}$. This figure is a graphical illustration of the positive granular residual term. As highlighted in Equation (5), the granular residual is a covariance between the firm-level value added growth and firm size. The 
Figure 2. Micro Responses to a $10 \%$ World Productivity Shock

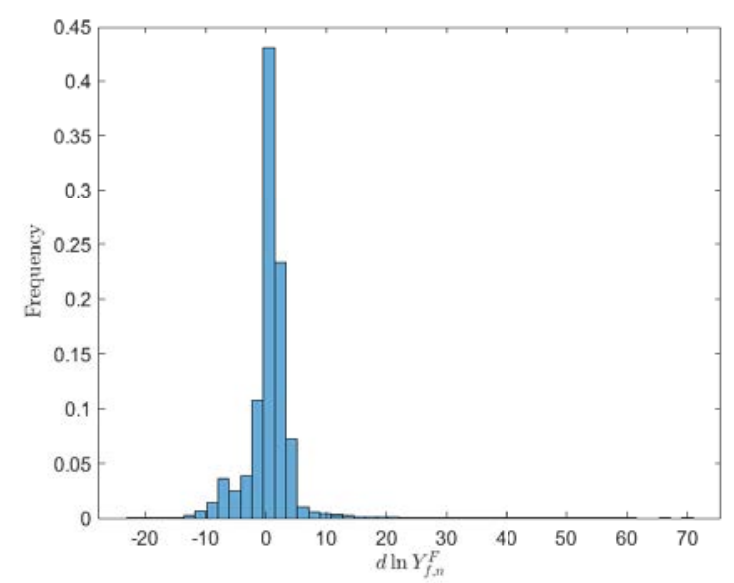

(a) Histogram of $d \ln Y_{f, n}^{F}$

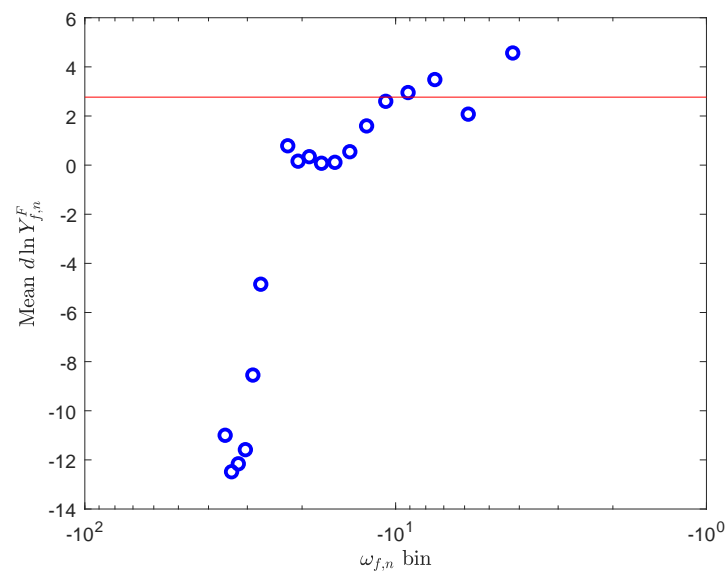

(b) Average $d \ln Y_{f, n}^{F}$ and $\omega_{f, n}$

Notes: This figure displays the firm responses to a $10 \%$ world productivity shock in the baseline model. Panel (a) is the histogram of $d \ln Y_{f, n}^{F}$. Panel (b) plots the mean $d \ln Y_{f, n}^{F}$, in percentage points, over firm size bins.

horizontal line plots the aggregate GDP change $d \ln Y_{n}^{F}$. It is notable that it is towards the top of the plot, coinciding with the $d \ln Y_{f, n}^{F}$ of the largest firms.

To illustrate the joint role of importing, exporting, and size in the propagation of foreign shocks, Figure 3 breaks up the firms in the data into four mutually exclusive categories: domestic-only, exporter-only, importer-only, and both importer and exporter. For each of these categories of firms, it shows the share in the total number of firms (blue bars), in total value added (orange), and in the total GDP change following the foreign productivity shock (yellow). The total GDP is simply the sum of all firms' value added (1), while the GDP change following a foreign shock is the value added share-weighted sum of firm growth rates (2). Thus the comparison of the orange and yellow bars reveals which firms have a disproportionately large role in the transmission of foreign shocks, relative to their overall GDP share. Domestic-only firms account for over $80 \%$ of all firms by count, and nearly $60 \%$ of aggregate value added, but their contribution to the GDP change due to a foreign shock is less than proportionate to their size, at about $46 \%$. By contrast, firms that are both importers and exporters are relatively few, but have a disproportionate share in the GDP impact of foreign shocks. Interestingly, there are comparatively fewer firms that only import or only export, compared to firms that do both. Those firms' GDP impact is smaller than their size. In fact, the exporter-only firms' contribution to the GDP change is negative - albeit quite small. This is sensible, as a foreign productivity shock makes foreign markets more competitive and reduces foreign demand. For exporter-only firms, this is not fully compensated by cheaper inputs.

Next, we evaluate the propagation of a foreign demand shock to France. To that end, we 
Figure 3. Size and Responsiveness to Foreign Productivity Shocks, by Firm Group

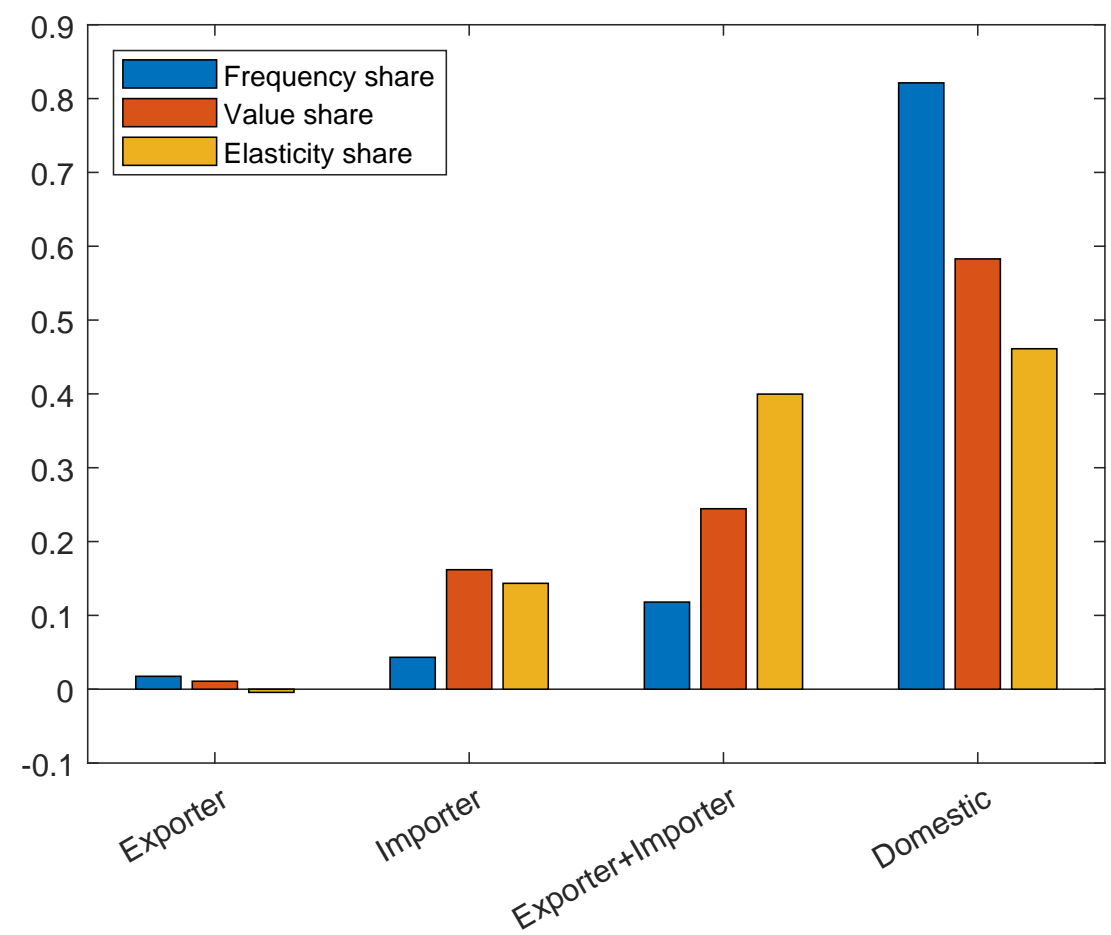

Notes: This figure the share of the number of firms (blue bars), of aggregate value added (orange bar), and the share of the total GDP change (yellow bars) following a foreign productivity shock accounted by each group of firms.

simulate an increase in the taste shock $\xi_{f, n m, j}$ to all firms in $n=$ France in all foreign markets $m \neq n$. Examining Equation (8), it is clear that an increase in the taste for all French firms abroad amounts to a $\widehat{\xi}_{n m, j}^{\frac{1}{\rho-1}}$ productivity increase for French exports abroad, and thus an increase in demand for French goods by foreign firms and consumers. (We assume that this is a purely external shock, such that the French domestic demand shifter $\xi_{f, n n, j}$ is unchanged.) We thus simulate a $10 \%$ shift in demand for French goods, namely $d \ln \xi_{n m, j}^{\frac{1}{\rho-1}}=0.1$.

The right panel of Table 3 reports the results. In the baseline, a 10\% demand shock for French goods abroad raises French real GDP by $0.35 \%$. This is a smaller GDP change than following a foreign productivity shock, but that is because the overall shock is much smaller, as it affects only the French tradable sector. The granular residual accounts for $47 \%$ of the overall impact for the foreign demand shock.

To evaluate whether the heterogeneity that produces the large granular residual is within or across sectors, we write the decomposition (3) at the sector level instead of the firm level:

$$
d \ln Y^{F}=\mathcal{E}_{\mathcal{J}}^{F}+\Gamma_{\mathcal{J}}^{F}
$$

where $\Gamma_{\mathcal{J}}^{F} \equiv \sum_{j} \omega_{j, n,-1} d \ln Y_{j, n}^{F}-\frac{1}{\mathcal{J}} \sum_{j} d \ln Y_{j, n}^{F}$ is the granular residual defined based on sectoral 
value added growth rates $d \ln Y_{j, n}^{F}$ and shares $\omega_{j, n,-1}$, and $\mathcal{E}_{\mathcal{J}}^{F}$ is the unweighted average sectoral growth rate. Importantly, we implement this decomposition on the baseline model featuring the full heterogeneity across firms, but use the sector-level shares and value added changes. Note that standard multi-sector models of international shock transmission would capture the sectoral granular residual. Thus, the sectoral granular residual is a natural benchmark for our firm-level results.

The results are presented in the panel labeled "Sector-Level Decomposition" of Table 3. By construction, the overall GDP change $d \ln Y^{F}$ is exactly the same as in the top panel of the table. Following a productivity shock, the sector-level granular residual of $23 \%$ is much smaller than the firm-level granular residual, suggesting that the impact of heterogeneity is to a large extent not captured by the sectoral dimension. For the foreign demand shock, the sectoral granular residual is actually strongly negative, accounting for $-70 \%$ of the overall effect for the demand shock. Evidently, sectors with the highest positive elasticities with respect to foreign demand tend to actually be relatively smaller in size. This is sensible, as some of the largest sectors in our data are non-tradable, and thus by construction not directly experiencing the increase in foreign demand.

Table A5 presents the results when deflating by CPI. The change in GDP is larger at $6.4 \%$ following the world shock. It is not surprising that deflating by the CPI produces a larger real GDP change, as the CPI includes reductions in the prices of imported goods. Since the movement in the aggregate price level is larger for the CPI than the GDP deflator, and enters entirely in $\mathcal{E}^{F}$, the $\mathcal{E}^{F}$ term is also larger. Nonetheless, the granular residual is still responsible for $34 \%$ of the total GDP change following a foreign productivity shock. When deflating by CPI, the foreign demand shock raises French GDP by $0.47 \%$, with the contribution of the foreign granular residual of $35 \%$.

The quantitative results in Table 3 are not driven by our choices of parameter values. Tables A6-A7 present the decomposition of the GDP change into the $\mathcal{E}^{F}$ and $\Gamma^{F}$ terms following the world productivity and demand shocks, respectively, while raising and lowering each key elasticity in the model. The foreign granular residual is quantitatively important under every alternative parameter value considered in the tables. Next, Tables A6-A7 report the results under flexible markups as in Atkeson and Burstein (2008). In this environment, firms take into account the impact of their own pricing decisions on the sectoral price index, and thus markups are heterogeneous across firms, with larger firms having higher markups. This alternative approach has no effect on the quantitative importance of the granular residual. Finally, we examine what happens when changes in aggregate profits $\Pi_{n}$ contribute to final demand. As we do not have firm ground to stand on when evaluating aggregate profit changes, in the baseline we assume that aggregate profits do not change following the foreign shock. In this robustness check, we instead assume that the total profits of firms operating in France equal the variable profits, which in turn are a constant fraction of the aggregate sales. Note that this approach gives profits the highest chance to make a difference, 
by assuming that variable profits are total profits, that is, there are no fixed costs. The last line of Tables A6-A7 reports the results, and shows that the granular residual remains quantitatively important.

Finally, we run the heuristic regression (6) inside the model. The results are reported in Table 1, columns 5 (for the world productivity shock) and 6 (world demand shock). Since the model simulation is of a single year's growth rate, there are fewer firms in this regression, and sector-time fixed effects become sector fixed effects. The model reproduces the pattern in the data qualitatively. Larger firms are more sensitive to both the world productivity and world demand shocks. Interestingly, the coefficient of interest is much smaller than in the data in the productivity shock simulation, but much larger than in the data in the demand shock simulation. Given that actual world GDP is a mix of productivity and demand shocks, we should not expect a single shock inside the model to replicate the data coefficient. The fact that the data coefficient is between those for productivity and demand shocks is perhaps telling that the foreign shocks experienced by France are a mixture of the two.

\subsubsection{Simulating Actual Foreign GDP Growth}

The above results explore the propagation into France of hypothetical shocks. To provide a closer comparison to actual GDP data, in this section we subject the French economy to actual foreign GDP growth rates. Because France trades with many partner countries, to compute the French economy's responses to worldwide economic conditions requires simulating shocks to multiple countries at once. We do this in two ways. First, we feed the TFP shocks to foreign countries from the Penn World Tables into the model. In the second approach, we obtain actual GDP growth for all the countries in our sample from the World Development Indicators. To compute the propagation of foreign GDP growth rates into France, we re-express the model directly in terms of elasticities of French firms to foreign GDP. The advantage of the latter approach is that it in principle accounts for all of GDP movements abroad, not just the movements in measured TFP. The disadvantage is that it implicitly attributes all of the foreign GDP changes to TFP, which may not be accurate. Appendix B.3 details the two procedures.

Table 4 reports the results for two time periods: 1975-2014, and 1995-2007. There are two reasons to focus on the shorter time period. The first is that for this time period we can report the standard deviation of the overall French granular residual $(\Gamma)$, sourced from our earlier work (di Giovanni et al., 2014). ${ }^{14}$ Second, our model is implemented on the trade and production data from this period, and it is not clear that the cross-border trade linkages we assume are realistic prior to the 1990s. The first two columns report the standard deviations of actual French GDP

\footnotetext{
${ }^{14}$ The overall granular residual is the contribution of all firm-level idiosyncratic shocks, including domestic ones, to aggregate sales fluctuations. Hence, it is more volatile than $\Gamma^{F}$, which is generated solely from propagation of aggregate foreign shocks.
} 
Table 4. Standard Deviations of Actual and Foreign-Induced GDP Growth and Its Components, Percentage Points

\begin{tabular}{|c|c|c|c|c|c|c|c|c|}
\hline \multirow[t]{2}{*}{ Period } & \multicolumn{2}{|c|}{ Data } & \multicolumn{3}{|c|}{ Foreign TFP } & \multicolumn{3}{|c|}{ Foreign GDP } \\
\hline & $d \ln Y$ & $\Gamma$ & $d \ln Y^{F}$ & $\mathcal{E}^{F}$ & $\Gamma^{F}$ & $d \ln Y^{F}$ & $\mathcal{E}^{F}$ & $\Gamma^{F}$ \\
\hline $1975-2014$ & 1.54 & & 0.17 & 0.05 & 0.12 & 0.13 & 0.04 & 0.09 \\
\hline 1991-2007 & 1.11 & 0.96 & 0.17 & 0.06 & 0.11 & 0.09 & 0.04 & 0.06 \\
\hline
\end{tabular}

Notes: The panel labeled "Data" reports the standard deviations of actual French GDP growth $(d \ln Y)$, and the actual French granular residual $(\Gamma)$. The panels labeled "Foreign TFP" and "Foreign GDP" report the standard deviations of French GDP generated purely from observed foreign TFP and GDP, respectively, and standard deviations of each component of (3). Foreign TFP growth rates are taken from the Penn World Tables, the French and foreign GDP growth from the World Development Indicators, and $\Gamma$ from di Giovanni et al. (2014).

growth and the granular residual. The middle panel reports the standard deviations $d \ln Y^{F}, \mathcal{E}^{F}$, and $\Gamma^{F}$ generated purely by foreign TFP shocks. Foreign TFP shocks by themselves can generate about $10-15 \%$ of the observed GDP fluctuations of France. More importantly for us, the standard deviation of the foreign granular residual $\Gamma^{F}$ is 65 to $71 \%$ of the overall standard deviation of the foreign shock-induced GDP fluctuations. By contrast, the standard deviation of the unweighted average component $\mathcal{E}^{F}$ is 29 to $35 \%$ of the total standard deviation. Thus, foreign shocks are indeed predominantly granular fluctuations. The right-most panel reports the results of feeding in GDP growth. The relative contribution of the foreign granular residual to the overall foreign impact is similarly close to $70 \%$.

Using different approaches, Gabaix (2011), di Giovanni et al. (2014), and Carvalho and Grassi (2019) document that a significant fraction of GDP fluctuations is driven by idiosyncratic shocks to individual firms. The contribution of firm idiosyncratic shocks to aggregate fluctuations is captured by the granular residual. Beyond accounting for aggregate fluctuations, the granular residual is an object of interest in other contexts; see for instance its use as an instrument (Gabaix and Koijen, 2019). Because of the systematically heterogeneous cross-border linkages across firms, foreign shocks are a quantitatively important contributor to the granular residual, and are thus one of the sources of granular fluctuations.

\subsection{Macro: the Attenuation Effect of Firm Heterogeneity}

We compare the baseline model to an alternative implementation that suppresses all within-sector firm heterogeneity: domestic and foreign sales shares (the $\pi_{f, n k, j}$ 's), intermediate import usage $\left(\pi_{f, m n, j i}^{M}\right)$, and labor shares $\left(\pi_{f, n, i}^{l}\right)$ are made identical across firms in each sector. To preserve 
comparability to the baseline, this model still has firms, that are homogeneous in their importing and exporting intensities. The $\pi_{f, m n, j i}^{M}$ 's and $\pi_{f, n, j}^{l}$ 's are set to match the sector-level imported input coefficients and labor shares, and the export shares $\pi_{f, n k, j}$ are set to match aggregate export shares in each sector. Importantly, this exercise preserves the overall levels of imports and exports, by sector, so this alternative model features the exact same level of trade openness as the baseline. This implies that the imported input coefficients in this implementation are lowered for the firms that in the data actually import inputs, but raised for firms that in the data do not. Similarly, firms that export nothing in the data export to all countries in this counterfactual scenario. This model can be implemented using only the WIOD sectoral production and trade data, and does not require any firm-level information.

Table 3 reports the results in the row labeled "Homogeneous firms." The main macro finding is that the aggregate GDP change following the world productivity shock is $22 \%$ larger in the homogeneous firm model than in the baseline. The attenuation effect also appears for the foreign demand shock, though here the disparity is smaller at $9 \%$. In all cases, the average-granular decomposition shows that the entirety of the GDP change is now accounted for by the unweighted average value added change $\mathcal{E}^{F}$, with zero contribution of the granular residual. Not surprisingly, the representative firm model is also very different at the micro level.

The attenuation effect is not unique to our preferred calibration. Table A8 presents the comparison of GDP changes in the baseline and homogeneous models following the world productivity and demand shocks, while raising and lowering each key elasticity in the model. The finding that GDP changes are larger in the homogeneous model obtains for every alternative parameter value considered in the table. The proportional differences in GDP changes between the homogeneous and baseline models are also similar to the main calibration, which does not stand out in terms of the relative magnitude of the attenuation effect. Next, Table A 8 reports the results under flexible markups as in Atkeson and Burstein (2008). As expected, flexible markups dampen somewhat the difference between the homogeneous and heterogeneous models, but a substantial attenuation effect still remains. Finally, the last line of Table A8 reports the results when changes in aggregate profits $\Pi_{n}$ contribute to final demand, and shows that the attenuation effect of heterogeneity persists.

\subsection{Connecting the Micro and the Macro}

We now connect the micro granular residual result to the macro attenuation result by exploiting the micro features of trade in the cross-section of countries. We subject our model to shocks in each foreign country separately, and perform the decomposition (3) of the French GDP change in response to country-specific shocks. Let $d \ln Y^{m}, \Gamma^{m}$, and $\mathcal{E}^{m}$ denote the change in France's GDP, the granular residual, and the unweighted value added change following a shock in country $m$. Figure 4 displays the results for $10 \%$ productivity shocks in each country separately. On the 
Figure 4. GDP Changes in Response to 10\% Country-Specific Productivity Shocks

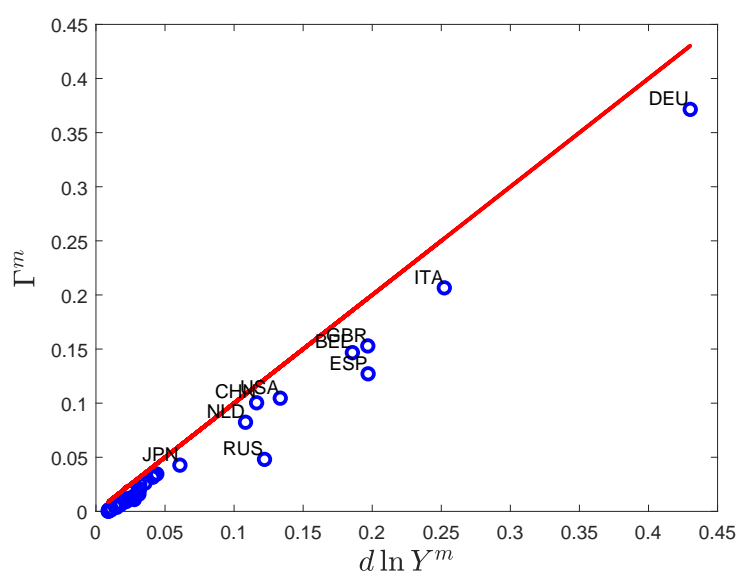

(a) $\Gamma^{m}$ vs. GDP change

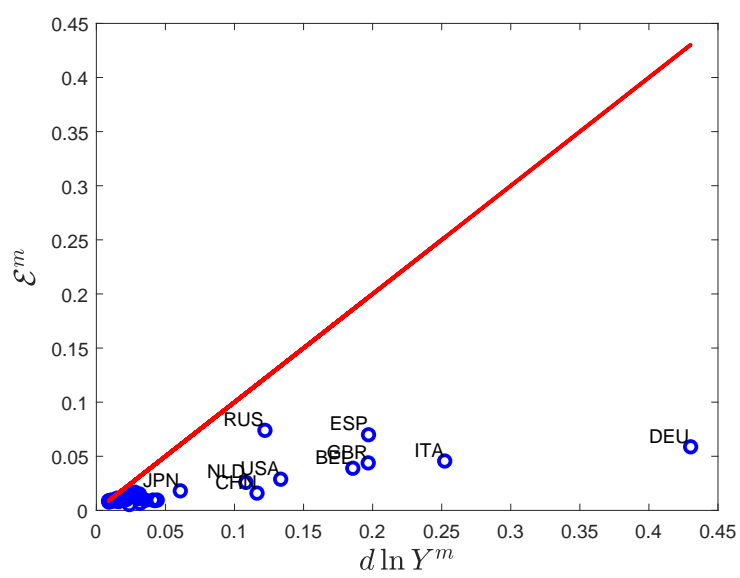

(b) $\mathcal{E}^{m}$ vs. GDP change

Notes: This figure plots the real GDP change in France on the y-axis following a country-specific shock against the $\Gamma^{m}$ (left panel) and $\mathcal{E}^{m}$ (right panel). A 45-degree line is added to both plots. All units are in percentage points.

$\mathrm{x}$-axis of both panels is the change in GDP. Not surprisingly, French GDP responds by different magnitudes to shocks in different countries, with the size of the response conditioned by country size and level of trade integration with France. The largest by a wide margin is the GDP response to a shock in Germany (DEU), which produces a 0.43\% change in French GDP. Smaller and more distant countries produce negligible GDP changes.

The second notable feature of the figure is that virtually all the variation in the overall GDP response is accounted for by the variation in the foreign granular residual (left panel). The observations are near the 45-degree line. The right panel is the scatterplot of $d \ln Y^{m}$ against $\mathcal{E}^{m}$. This term is on average closer to zero, and does not capture well the overall GDP change.

We next show that the size of the granular residual accounts for the relative magnitude of the attenuation effect. Let $d \ln Y^{H O M, m}$ be the GDP change following a country $m$ shock in a counterfactual model in which trade with that country is homogeneous across firms within each sector. Figure 5 plots the size of the attenuation effect $d \ln Y^{H O M, m} / d \ln Y^{m}$ against the relative importance of the granular residual, $\Gamma^{m} / d \ln Y^{m}$. There is quite a bit of variation in the relative importance of the foreign granular residual across countries. For example, for a German or Chinese shock $\Gamma^{m}$ accounts for almost $90 \%$ of the total change in French GDP. By contrast, for an Australian or a Russian shock, the granular residual accounts for about $40 \%$ of the total GDP change. This suggests that the micro patterns of trade with different countries affect the relative importance of the $\Gamma^{m}$ term: trade with Germany is more granular than trade with Australia. The positive relationship between the relative size of $\Gamma^{m}$ and the magnitude of the attenuation effect - the 
Figure 5. The Attenuation Effect and the Relative Importance of the Granular Residual

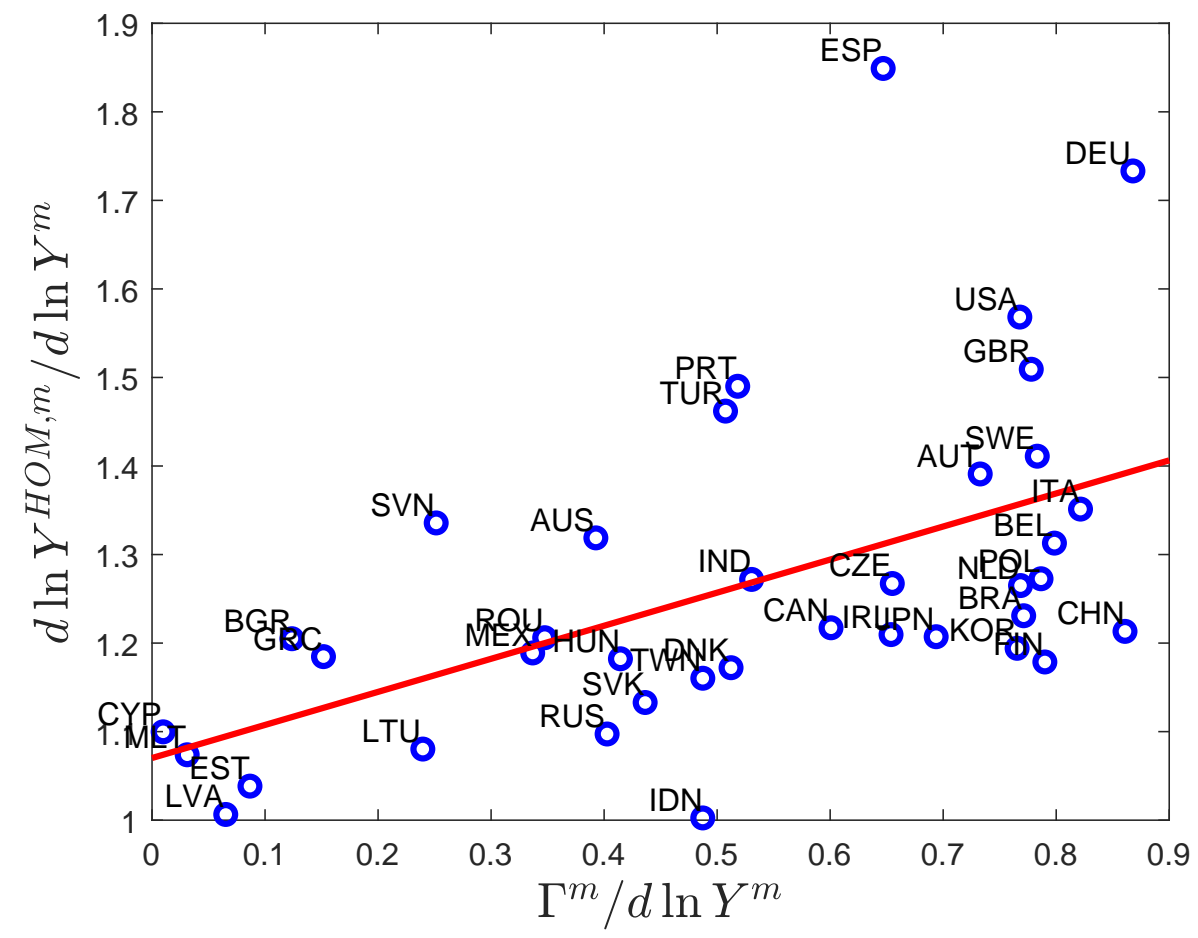

Notes: This figure displays the size of the attenuation effect, $d \ln Y^{H O M, m} / d \ln Y^{m}$ against the relative importance of the granular residual, $\Gamma^{m} / d \ln Y^{m}$.

correlation is 0.53 - illustrates the connection between the micro and the macro. Countries for which the granular residual is relatively important - a micro-level feature of the country-specific trade relationships - also exhibit a stronger attenuation effect at the macro level.

The granular residual is a covariance between size and the firm-level response to a foreign shock. We argued that the granular residual is a consequence of the size-biased participation in international trade: larger firms are more sensitive to foreign shocks because they trade more internationally. The cross-country dimension allows us to illustrate this mechanism more clearly. Figure 6 plots the relative importance of the granular residual following a shock to country $m$, $\Gamma^{m} / d \ln Y^{m}$, against the covariance between firm size and importing intensity from country $m$, $\operatorname{Cov}\left(\frac{\omega_{f, n}}{\bar{\omega}}, \frac{\pi_{f, m n}^{M}}{\pi_{j, m n}^{M}}\right)$ (left panel) and size and exporting intensity to country $m, \operatorname{Cov}\left(\frac{\omega_{f, m}}{\bar{\omega}}, \frac{s_{f, n m}^{X}}{s_{j, n m}^{X}}\right)$ (right panel). We normalize the import intensity of the firm $\pi_{f, m n}^{M}$ by the import intensity of the sector $j$ in which it operates, and do the same for export intensity $s_{f, n m}^{X}$. Both relationships are positive, with the importing dimension more pronounced.

In words, when trade with country $m$ is relatively concentrated among larger firms, the granular residual following a shock to that country is higher (Figure 6). In turn, a larger granular residual 
Figure 6. The Granular Residual and Trade Participation
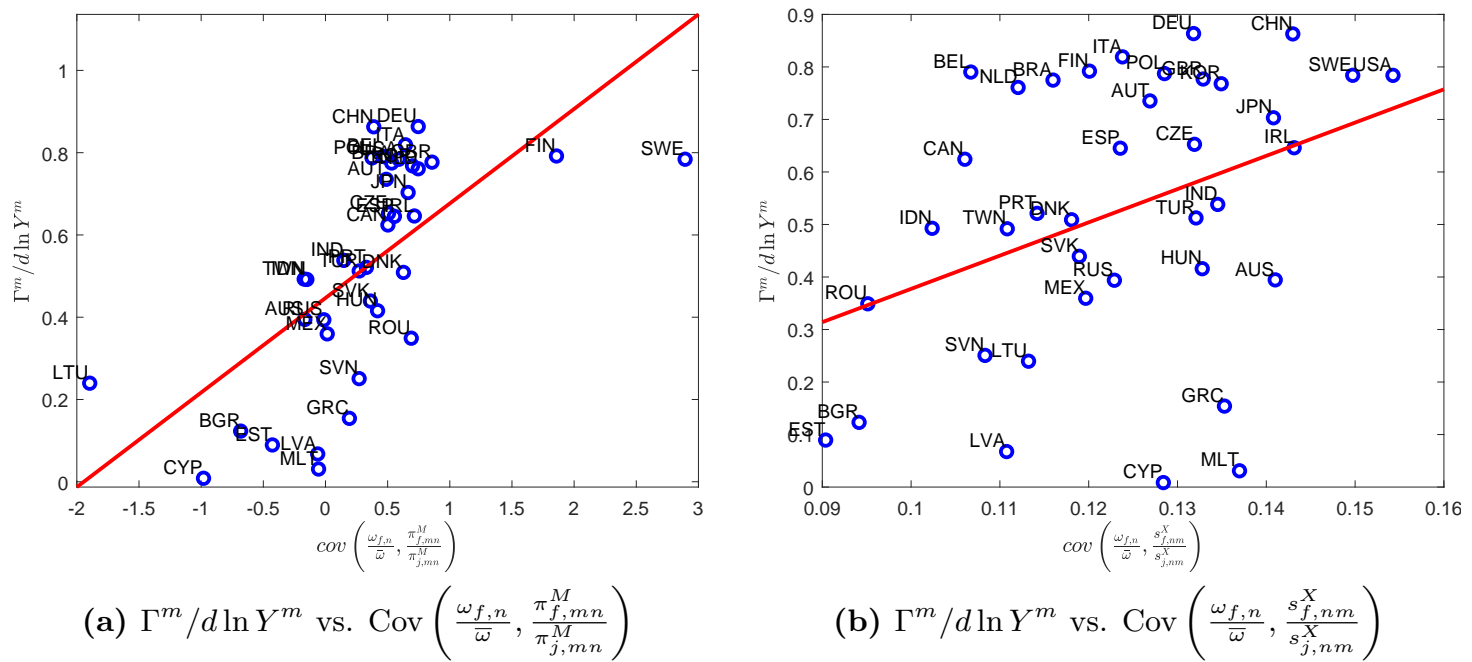

Notes: This figure plots the relative size of the granular residual following a shock in country $n, \Gamma^{m} / d \ln Y^{m}$, against the covariance between size and importing intensity (left panel) and the covariance between size and importing intensity (right panel).

means greater attenuation of foreign shocks compared to a world with homogeneous firms (Figure 5).

\subsection{Understanding the Mechanisms}

The baseline model differs from the homogeneous firm model in two respects: (i) heterogeneous sales across firms by destination, and (ii) heterogeneous production functions across firms within a sector, reflected in firm-specific labor and input shares. We investigate the consequences of these two sources of heterogeneity in turn. First, we prove analytically that if production functions are identical across firms within a sector, the real GDP change due to a foreign shock is invariant to the distribution of market shares across firms. This theoretical result provides a sharp characterization of the source of the attenuation effect: a necessary condition for attenuation is heterogeneity in the production functions. Though we do not have an analytical result on how production function heterogeneity affects the size of the GDP response to foreign shocks, we next provide a heuristic illustration for how this dimension of heterogeneity generates attenuation.

\section{Exporting/sales heterogeneity.}

Proposition 1 If $\gamma_{f, m n, i j}=\gamma_{m n, i j}$ and $\alpha_{f, n, j}=\alpha_{n, j} \forall f$, the real GDP change following a foreign productivity shock or a non-firm-specific foreign demand shock is invariant to the distribution of firm-level destination-specific sales shares $\pi_{f, n k, j}$. 


\section{Proof: See Appendix B.4.}

The proof proceeds to show that as long as within-sector production functions are identical across firms, the sector-destination-level equations that must be satisfied in equilibrium do not have firm-level sales shares $\pi_{f, n k, j}$ in them, and therefore the macro aggregates are independent of either initial or post-shock $\pi_{f, n k, j}$ 's. The proof covers all distributions of $\pi_{f, n k, j}$ 's, including zero market shares. This implies that any extensive margin differences across model implementations, whereby firms do or do not serve all or some markets have no effect on GDP changes due to foreign shocks if these firms have the same production functions.

The proposition applies in our quantitative framework, which is general in some respects such as unrestricted distributions of $\pi_{f, n k, j}$ and foreign input usage by source country and sector but relies on some key assumptions, notably constant markups. If larger firms had systematically different markups, as in Atkeson and Burstein (2008) for instance, then the GDP change would not be invariant to the size distribution within a sector even if all firms had identical production functions. Nonetheless, the constant markup case is an important benchmark, and Proposition 1 clarifies the conditions under which different types of firm heterogeneity matter. In the robustness exercises above we showed that variable markups à la Atkeson and Burstein (2008) do not overturn the macro attenuation result.

Importing/production function heterogeneity. Having established that sales heterogeneity will not deliver different GDP responses to foreign shocks absent production function heterogeneity, we now investigate how production function heterogeneity can lead to attenuation.

The intuition is as follows. Raising a firm's imported input share lowers its impact on domestic GDP. This is because mechanically, a higher imported input share means lower demand for domestic value added by the firm. At the same time, raising a firm's imported input share increases its exposure to foreign shocks. Thus, relative to a representative firm world, introducing heterogeneity in imported input shares induces a negative covariance in the cross section of firms between impact on domestic GDP and exposure to foreign shocks. This negative covariance is the source of the attenuation effect of production function heterogeneity.

To make this more precise, we begin by noting that the foreign productivity shock is a marginal cost shock from the perspective of French firms. Recall that firm $f$ 's marginal cost is given by:

$$
M C_{f}^{-1}=\frac{a_{f}}{b_{f}}
$$

where $b_{f}$ is the firm-specific input bundle cost given by (9). (It will be expositionally convenient to work with the inverse of the marginal cost, since we consider a positive shock to foreign productivity.) The first building block of the argument is that firms importing more foreign inputs experience a larger marginal cost shock when foreign productivity changes. Differences across firms 
in value added growth following a foreign shock come from differential reductions in input prices:

$$
d \ln M C_{f}^{-1} \propto \sum_{i} \sum_{k}\left(1-\pi_{f, n, j,-1}^{l}\right) \pi_{f, m n, i j,-1}^{M} d \ln P_{m n, i}^{-1}
$$

since, modulo differences in labor shares, the other terms that enter value added growth - such as market-specific demand changes - are common to all firms. Firms with larger import shares $\left(1-\pi_{f, n, j,-1}^{l}\right) \pi_{f, m n, i j}^{M}, m \neq n$ experience a de facto bigger marginal cost shock following a foreign productivity improvement.

The second building block of the argument is that a given shock to a firm has a smaller impact on domestic GDP the higher is that firm's imported input share. To make this statement precise, define firm $f$ 's influence as the elasticity of GDP with respect to the inverse marginal cost of the firm: $\quad \lambda_{f} \equiv \frac{d \ln Y_{n}}{d \ln M C_{f}^{-1}} \cdot{ }^{15}$ Let $\pi_{f, I M}^{M} \equiv \sum_{m \neq n} \sum_{i} \pi_{f, m n, j i}^{M}$ denote the total imported input share of firm $f$. Below, we will show by means of numerical illustrations that holding firm size fixed, influence decreases in $\pi_{f, I M}^{M}$. That is, all else equal a firm that has a higher import share has a lower influence on domestic GDP: $\partial \lambda_{f} / \partial \pi_{f, I M}^{M}<0$. This is intuitive since a higher import share mechanically means a lower share of domestic value added in production.

With this notation, we can now compare the homogeneous and the heterogeneous firm models. Write the change in GDP due to a vector of firm-specific marginal cost changes that follow a foreign productivity shock as $d \ln Y_{n}=\sum_{f} \lambda_{f} d \ln M C_{f}^{-1}$. We can rewrite it as the sum of averages and a covariance: $d \ln Y_{n}=\frac{\lambda}{N} \sum_{f} d \ln M C_{f}^{-1}+N \operatorname{Cov}\left(\lambda_{f}, d \ln M C_{f}^{-1}\right)$, where $\lambda$ is the elasticity of GDP with respect to an aggregate across-the-board marginal cost shock. In the homogeneous firm model, there is no variation across firms (within a sector) in either $\lambda_{f}$ or $d \ln M C_{f}$, thus the covariance term $\operatorname{Cov}\left(\lambda_{f}, d \ln M C_{f}^{-1}\right)$ is zero. By contrast, in the heterogeneous firm model the relationship between $d \ln M C_{f}$ and $\lambda_{f}$ is negative in the cross-section of firms: $\operatorname{Cov}\left(\lambda_{f}, d \ln M C_{f}^{-1}\right)<0$ (conditional on size). Firms importing a lot of inputs have a larger marginal cost change following a foreign shock, but less influence on domestic GDP. This negative relationship between influence and exposure to the shock drives down the response of GDP to foreign shocks in the heterogeneous firm model.

Since this mechanism has not to our knowledge been previously pointed out, we start by illustrating it via the simplest possible example: a model with 2 countries (France and the Rest of the World), 2 sectors (Tradables and Non-Tradables), and 2 firms in each sector. To isolate the impact of heterogeneity in imported input intensity, we assume that within each sector these firms have the same sales to all markets, and are thus the same size. We start with the homogeneous firm model, in which both firms in each sector have the exact same imported input coefficients. We

\footnotetext{
${ }^{15}$ This definition is somewhat heuristic because each firm's marginal cost is of course partly a function of general equilibrium objects such as factor prices. To make this definition compatible with general equilibrium, we can think of $\lambda_{f}$ as the elasticity of domestic GDP with respect to the exogenous components of the firm's marginal costs, such as foreign productivity, or the firm's own productivity. Indeed, the term "influence" normally refers to the elasticity of GDP with respect to firm $f$ 's own productivity $a_{f}$ (e.g. Acemoglu et al., 2012). Since the marginal cost is log-linear in $a_{f}$ (eq. (15)), our definition subsumes the traditional definition.
} 
Figure 7. Influence and Shock Size as Import Intensity Changes

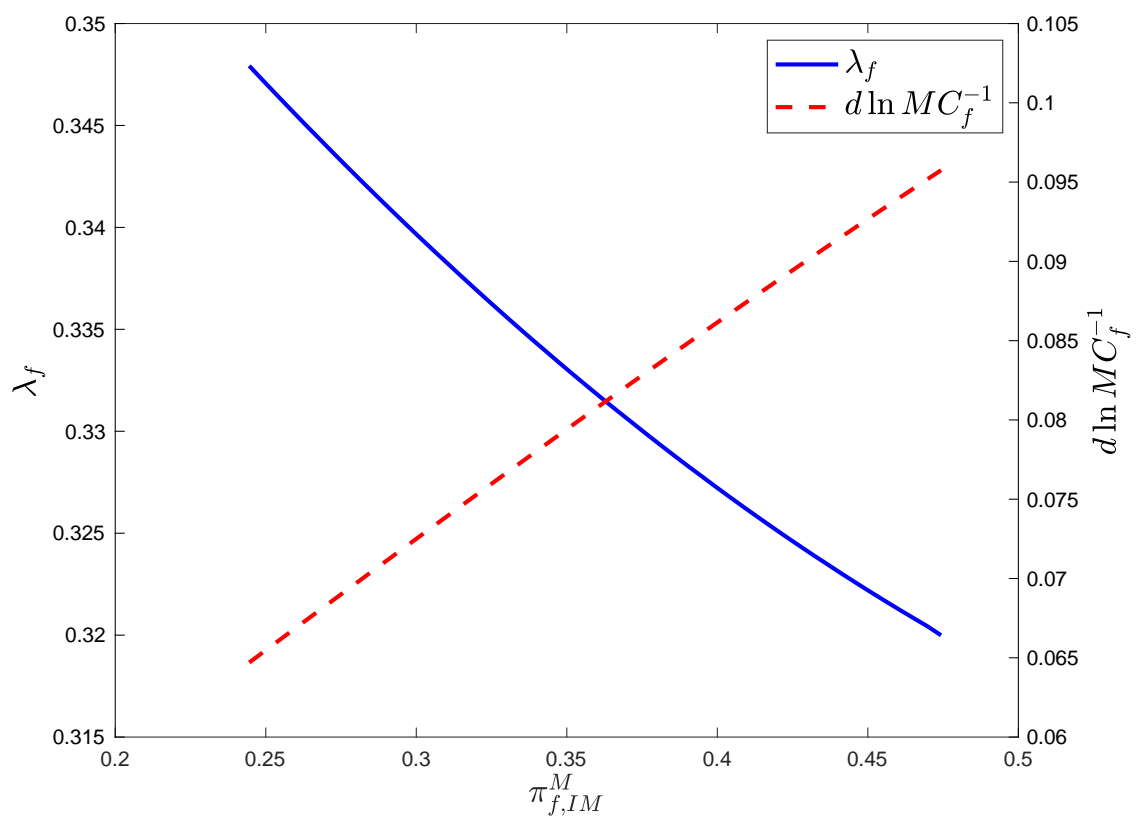

Notes: This figure displays $d \ln M C_{f}^{-1}$ and $\lambda_{f}$ for Firm 1 in the tradable sector as a function of imported input intensity.

then progressively reassign foreign inputs to Firm 1 in each sector, so that in the final simulation Firm 1 accounts for virtually all of its sector's imports and Firm 2 sources nearly all of its inputs domestically. Importantly, as we make import participation heterogeneous across firms within a sector, we keep this economy's overall trade openness in each sector constant. Appendix B.5 details the calibration. The sectoral output and trade shares are set to match the WIOD.

Even this simple example delivers the same result as in the full quantitative model that the GDP change is larger in the homogeneous case than in the heterogeneous one. Figure 7 plots the Tradable sector Firm 1's $d \ln M C_{f}^{-1}$ and $\lambda_{f}$ as a function of its imported input intensity on the $\mathrm{x}$-axis. As we move from left to right in the plot, Firm 1's imported input intensity rises (and in the background, Firm 2's import intensity falls). As argued above, increasing a firm's import intensity attenuates its domestic influence (solid blue line), while at the same time increasing the size of the shock that it experiences (dashed red line). ${ }^{16}$

While in the $2 \times 2 \times 2$ example we could keep the size of all firms the same, in the data firms also differ dramatically in size. Firm size has a first-order effect on influence: the larger the firm, the greater its influence. At the same time, since larger firms tend to have higher imported input intensities, their influence is relatively lower than it would have been if all imported input shares

\footnotetext{
${ }^{16}$ To compute $\lambda_{f}$, we use the fact that marginal cost is a function of productivity (eq. (15)). We thus calculate the elasticity of GDP with respect to a productivity shock to Firm 1 under the different import shares.
} 
were the same within a sector. To illustrate this, we consider an alternative homogeneous counterfactual model, in which production functions are identical across firms, but firm sizes (governed by the $\pi_{f, m n, j}$ 's) are still given by the data. By Proposition 1, since production functions are identical across firms, the GDP change following a foreign shock is invariant to the distribution of the $\pi_{f, m n, j}$ 's, and hence to the distribution of firm size. Thus, the GDP change in this intermediate model is identical to the GDP change in the "Homogeneous firms" model reported in Table 3. At the same time, because the firm sales distribution in this counterfactual model coincides with the fully heterogeneous firm baseline, we can compare the influence of the firms of different sizes to their influence in the baseline model.

Figure 8 plots the combined influence of the firms in the top 1\% (right side of the plot, labeled 99100), the "next 9\%" (middle, 90-99), and the bottom $90 \%$ of firms. The solid blue line displays the ratio of the relative influences of each category of firms in the baseline model to the homogeneous importing model $\left(\lambda^{H E T} / \lambda^{H O M}\right) .{ }^{17}$ There is a downward-sloping relationship: in the baseline model, larger firms are relatively less influential compared to the world in which they had the same trade intensity as everyone else. At the same time, of course, they are also more exposed to the foreign shock, as illustrated by the relative change in their inverse marginal cost (dashed red line). Thus, Figure 8 illustrates the attenuation effect along the firm size dimension. The largest firms are the most affected by the foreign shock, but are relatively less influential due to their higher import intensity. ${ }^{18}$

\footnotetext{
${ }^{17}$ To do this, we select the top $1 \%$ (the next $9 \%$, the bottom $90 \%$ ) of firms by total value added in each sector, and shock all the top $1 \%$ (the next $9 \%$, the bottom $90 \%$ ) firms at the same time. For each model, we normalize the influence of a particular category of firms by the elasticity of GDP with respect to an aggregate across-the-board marginal cost shock $\lambda=\sum_{f} \lambda_{f}$.

${ }^{18}$ In an economy with fixed factor supplies and perfect competition, $\lambda_{f}$ is equal to the Domar weight (Hulten, 1978; Acemoglu et al., 2012), a property that extends to the open economy (Baqaee and Farhi, 2019c). That is, a sector/firm's influence on GDP is invariant to its import and export intensities. This invariance result does not hold in our framework. In the illustrative $2 \times 2 \times 2$ model, we keep the total firm sales unchanged as input coefficients vary. Thus the Domar weights, reported in Table A4, are constant for each firm by construction. However, Figure 7 shows that the influence $\lambda_{f}$ changes with the firm's import intensity. Figure 8 further underscores the departure of our model from the benchmark where $\lambda_{f}$ equals the Domar weight. Because all the Domar weights are exactly the same in the two scenarios, the ratio of Domar weights between the two models is simply constant at 1 by construction. However, changing production functions affects the true influence of firms, systematically along the firm size dimension. Conceptually, the two reasons that $\lambda_{f}$ is not equal to the Domar weight are endogenous factor supply and profits. Both of these features are part and parcel of business cycle models. Endogenous labor supply has been a standard ingredient of macro models since the inception of modern macroeconomics (Kydland and Prescott, 1982). While imperfect competition is a less universal feature, important traditions in the macro literature, such as the New Keynesian paradigm (Galí, 2008), or the new open economy macro (Obstfeld and Rogoff, 1995) incorporate monopolistic competition. It may be a quantitative question of whether our result holds only for special values of the parameters that determine the labor supply elasticity and the profit share in GDP. Appendix Table A8 varies both sets of parameters (the Frisch elasticity that determines the labor supply response, and the Melitz elasticity $\rho$ that governs the profit share), and shows that our attenuation result holds for a range of parameter values.
} 
Figure 8. Influence, Exposure to Foreign Shock, and Firm Size in the Baseline vs. Homogeneous Production Function Models

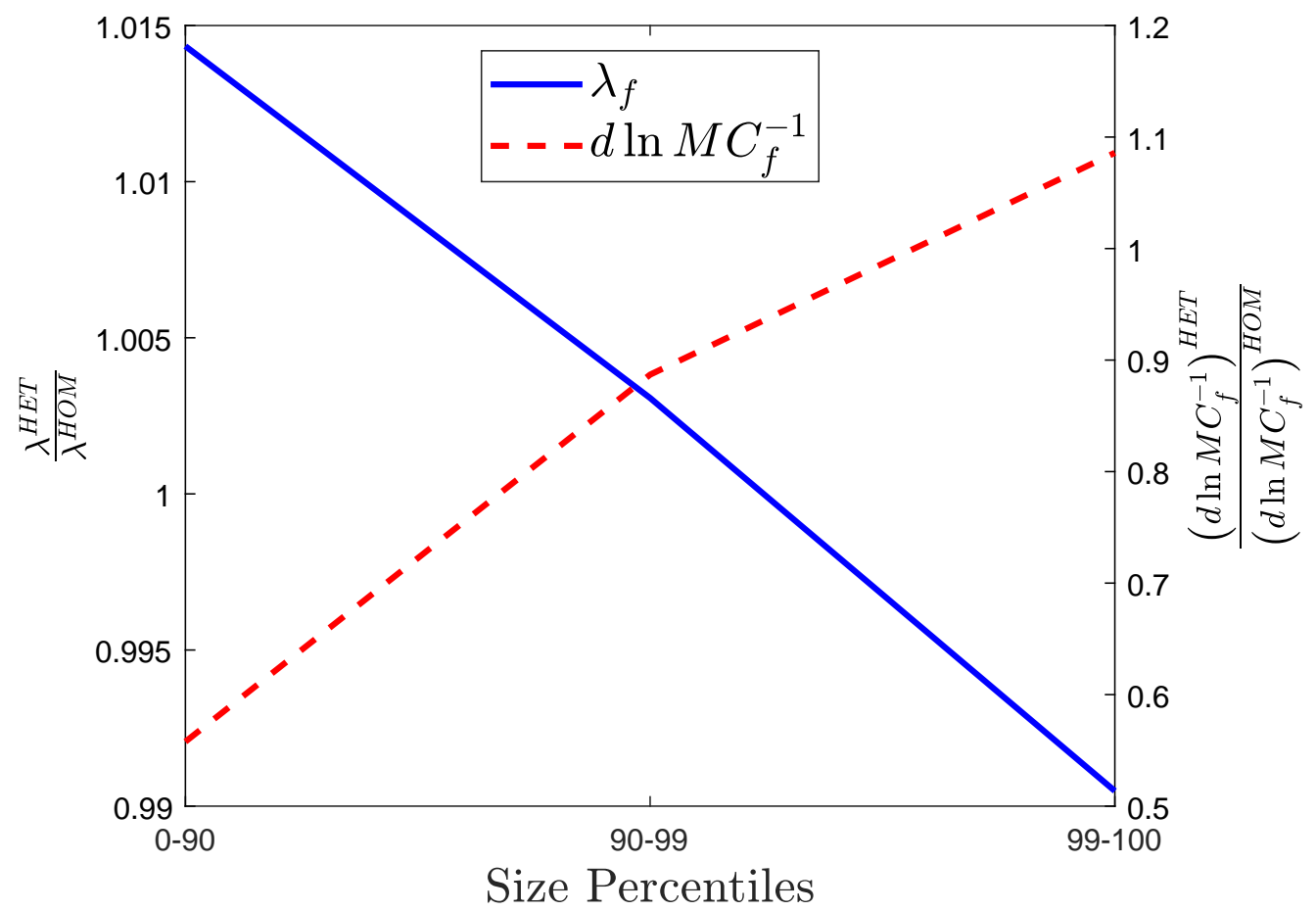

Notes: The solid (blue) line displays the ratio $\lambda^{H E T} / \lambda^{H O M}$ for the bottom $90 \%$, the 90th-99th percentile, and the top $1 \%$ of firms, where $\lambda^{H O M}$ is the influence on GDP of the percentile of firms in the homogeneous production function case, and $\lambda^{H E T}$ is the same percentile's influence on GDP in the baseline case. The dashed (red) line displays the ratio of inverse marginal cost changes in the two models for the same firm percentiles. 


\section{Conclusion}

Large firms are more likely to import and export. A natural conjecture is that this greater participation in international markets also makes the large firms more sensitive to foreign shocks. In this paper, we explored both the micro and the macro implications of this joint heterogeneity in size and international linkages. We first provided firm-level econometric evidence that larger firms are indeed more correlated with foreign GDP growth. We then implemented a quantitative multicountry model in which French firms exhibit the observed joint distribution of size, importing, and exporting.

We reported one micro and one macro finding. The micro finding is that foreign shocks manifest themselves as largely granular fluctuations in France. Large firms are thus the key channel through which foreign shocks propagate to the domestic economy. The macro finding is that the heterogeneity in trade participation actually attenuates the impact of a given foreign shock on French GDP. This is because heterogeneity in importing behavior induces a negative covariance between the size of the shock experienced by the firm and its contribution to domestic GDP, controlling for size. 


\section{References}

Acemoglu, Daron, Ufuk Akcigit, and William Kerr, "Networks and the Macroeconomy: An Empirical Exploration," NBER Macroeconomics Annual 2015, 2016, 30, 276-335.

_, Vasco M. Carvalho, Asuman Ozdaglar, and Alireza Tahbaz-Salehi, "The Network Origins of Aggregate Fluctuations," Econometrica, September 2012, 80 (5), 1977-2016.

Alessandria, George and Horag Choi, "Do Sunk Costs of Exporting Matter for Net Export Dynamics?," Quarterly Journal of Economics, 2007, 122 (1), 289-336.

Alvarez, Fernando and Robert E., Jr. Lucas, "General Equilibrium Analysis of the Eaton-Kortum Model of International Trade," Journal of Monetary Economics, September 2007, 54 (6), 17261768.

Atalay, Enghin, "How Important Are Sectoral Shocks?," American Economic Journal: Macroeconomics, October 2017, 9 (4), 254-280.

Atkeson, Andrew and Ariel Burstein, "Trade Costs, Pricing-to-Market, and International Relative Prices," American Economic Review, December 2008, 98 (5), 1998-2031.

Backus, David K., Patrick J. Kehoe, and Finn E. Kydland, "International Business Cycles: Theory and Evidence," in Thomas Cooley, ed., Frontiers of business cycle research, Princeton: Princeton University Press, 1995, pp. 331-356.

Baqaee, David Rezza, "Cascading Failures in Production Networks," Econometrica, September 2018, 86 (5), 1819-1838.

- and Emmanuel Farhi, "The Macroeconomic Impact of Microeconomic Shocks: Beyond Hulten's Theorem," Econometrica, July 2019, 87 (4), 1155-1203.

_ and _, "Macroeconomics with heterogeneous agents and input-output networks," January 2019. mimeo, UCLA and Harvard.

_ and _, "Networks, Barriers, and Trade," July 2019. NBER Working Paper 26108.

Barrot, Jean-Noël and Julien Sauvagnat, "Input Specificity and the Propagation of Idiosyncratic Shocks in Production Networks," Quarterly Journal of Economics, 2016, 131 (3), 1543-1592.

Bems, Rudolfs, Robert C Johnson, and Kei-Mu Yi, "Demand Spillovers and the Collapse of Trade in the Global Recession," IMF Economic Review, December 2010, 58 (2), 295-326.

Bigio, Saki and Jennifer La'O, "Distortions in Production Networks," Quarterly Journal of Economics, November 2020, 135 (4), 2187-2253.

Blaum, Joaquin, "Global Firms in Large Devaluations," June 2019. Mimeo, Brown University.

_, Claire Lelarge, and Michael Peters, "The Gains from Input Trade with Heterogeneous Importers," American Economic Journal: Macroeconomics, October 2018, 10 (4), 77-127.

Boehm, Christoph E., Aaron Flaaen, and Nitya Pandalai-Nayar, "Input Linkages and the Transmission of Shocks: Firm-Level Evidence from the 2011 Tōhoku Earthquake," Review of Economics and Statistics, 2019, 101 (1), 60-75.

Broda, Christian and David Weinstein, "Globalization and the Gains from Variety," Quarterly Journal of Economics, May 2006, 121 (2), 541-85.

Burstein, Ariel and Javier Cravino, "Measured Aggregate Gains from International Trade," American Economic Journal: Macroeconomics, April 2015, 7 (2), 181-218.

_, Christopher Kurz, and Linda L. Tesar, "Trade, Production Sharing, and the International Transmission of Business Cycles," Journal of Monetary Economics, 2008, 55, 775-795. 
_, Vasco M. Carvalho, and Basile Grassi, "Bottom-up Markup Fluctuations," October 2020. mimeo, UCLA, Cambridge, and Bocconi.

Caliendo, Lorenzo, Fernando Parro, Esteban Rossi-Hansberg, and Pierre-Daniel Sarte, "The Impact of Regional and Sectoral Productivity Changes on the U.S. Economy," Review of Economic Studies, 12 2017, 85 (4), 2042-2096.

Carvalho, Vasco M., "Aggregate Fluctuations and the Network Structure of Intersectoral Trade," October 2010. Mimeo, CREi and Universitat Pompeu Fabra.

- and Basile Grassi, "Large Firm Dynamics and the Business Cycle," American Economic Review, April 2019, 109 (4), 1375-1425.

_, Makoto Nirei, Yukiko U. Saito, and Alireza Tahbaz-Salehi, "Supply Chain Disruptions: Evidence from the Great East Japan Earthquake," Quarterly Journal of Economics, May 2021, 136 (2), 1255-1321.

Chaney, Thomas, "Distorted Gravity: The Intensive and Extensive Margins of International Trade," American Economic Review, September 2008, 98 (4), 1707-1721.

Chetty, Raj, Adam Guren, Day Manoli, and Andrea Weber, "Does Indivisible Labor Explain the Difference between Micro and Macro Elasticities? A Meta-Analysis of Extensive Margin Elasticities," NBER Macroeconomics Annual, 2013, 27 (1), 1 - 56.

Costinot, Arnaud and Andrés Rodríguez-Clare, "Trade Theory with Numbers: Quantifying the Consequences of Globalization," in Gita Gopinath, Elhanan Helpman, and Kenneth Rogoff, eds., Handbook of International Economics, Vol. 4, Elsevier, 2014, chapter 4, pp. 197-261.

Cravino, Javier and Andrei A. Levchenko, "Multinational Firms and International Business Cycle Transmission," Quarterly Journal of Economics, May 2017, 132 (2), 921-962.

Dekle, Robert, Jonathan Eaton, and Samuel Kortum, "Global Rebalancing with Gravity: Measuring the Burden of Adjustment," IMF Staff Papers, July 2008, 55 (3), 511-540.

Desai, Mihir A., C. Fritz Foley, and James R. Hines Jr., "A Multinational Perspective on Capital Structure Choice and Internal Capital Markets," The Journal of Finance, 2004, 59 (6), 24512487.

Dhyne, Emmanuel, Ken Kikkawa, Magne Mogstad, and Felix Tintelnot, "Trade and Domestic Production Networks," Review of Economic Studies, 2021, 88 (2), 643-668.

di Giovanni, Julian and Andrei A. Levchenko, "Putting the Parts Together: Trade, Vertical Linkages, and Business Cycle Comovement," American Economic Journal: Macroeconomics, April 2010, 2 (2), 95-124.

- and _, "Country Size, International Trade, and Aggregate Fluctuations in Granular Economies," Journal of Political Economy, December 2012, 120 (6), 1083-1132.

_ , _, and Isabelle Mejean, "Firms, Destinations, and Aggregate Fluctuations," Econometrica, July 2014, 82 (4), 1303-1340.

${ }_{-}, \ldots$, and _ , "Large Firms and International Business Cycle Comovement," American Economic Review: Papers $\& 3$ Proceedings, May 2017, $10^{7}$ (5), 598-602.

_ , _, and _, "The Micro Origins of International Business Cycle Comovement," American Economic Review, January 2018, 108 (1), 82-108.

Eaton, Jonathan, Samuel Kortum, and Brent Neiman, "Obstfeld and Rogoff's international macro puzzles: a quantitative assessment," Journal of Economic Dynamics and Control, 2016, 72 (C), $5-23$.

_ , _ , , and John Romalis, "Trade and the Global Recession," American Economic Review, November 2016, 106 (11), 3401-38. 
_ , Samuel S. Kortum, and Sebastian Sotelo, "International Trade: Linking Micro and Macro," NBER Working Papers 17864, National Bureau of Economic Research, Inc February 2012.

Feenstra, Robert C., Philip Luck, Maurice Obstfeld, and Katheryn N. Russ, "In Search of the Armington Elasticity," Review of Economics and Statistics, 2018, 100 (1), 135-150.

Foerster, Andrew T., Andreas Hornstein, Pierre-Daniel G. Sarte, and Mark W. Watson, "Aggregate Implications of Changing Sectoral Trends," August 2019. Forthcoming, Journal of Political Economy.

_ , Pierre-Daniel G. Sarte, and Mark W. Watson, "Sectoral vs. Aggregate Shocks: A Structural Factor Analysis of Industrial Production," Journal of Political Economy, February 2011, 119 (1), $1-38$.

Freund, Caroline and Martha Denisse Pierola, "Export Superstars," Review of Economics and Statistics, 2015, 97 (5), 1023-1032.

Gabaix, Xavier, "The Granular Origins of Aggregate Fluctuations," Econometrica, May 2011, 79 (3), 733-772.

- and Ralph S. J. Koijen, "Granular Instrumental Variables," April 2019. mimeo, Harvard and Chicago Booth.

Galí, Jordi, Monetary Policy, Inflation and the Business Cycle: An Introduction to the New Keynesian Framework, Princeton University Press, 2008.

Gaubert, Cecile and Oleg Itskhoki, "Granular Comparative Advantage," Journal of Political Economy, March 2021, 129 (3), 871-939.

Ghironi, Fabio and Marc J. Melitz, "International Trade and Macroeconomic Dynamics with Heterogeneous Firms," Quarterly Journal of Economics, August 2005, 120 (3), 865-915.

Grassi, Basile, "IO in I-O: Size, Industrial Organization, and the Input-Output Network Make a Firm Structurally Important," December 2017. mimeo, Bocconi.

Greenwood, Jeremy, Zvi Hercowitz, and Gregory W Huffman, "Investment, Capacity Utilization, and the Real Business Cycle," American Economic Review, June 1988, 78 (3), 402-17.

Hulten, Charles R., "Growth Accounting with Intermediate Inputs," Review of Economic Studies, October 1978, $45(3), 511-518$.

Hummels, David, Jun Ishii, and Kei-Mu Yi, "The Nature and Growth of Vertical Specialization in World Trade," Journal of International Economics, June 2001, 54, 75-96.

Huneeus, Federico, "Production Network Dynamics and the Propagation of Shocks," December 2018. mimeo, Yale University.

Huo, Zhen, Andrei A. Levchenko, and Nitya Pandalai-Nayar, "International Comovement in the Global Production Network," June 2019. NBER Working Paper 25978.

_, Andrei A Levchenko, and Nitya Pandalai-Nayar, "Utilization-Adjusted TFP Across Countries: Measurement and Implications for International Comovement," February 2020. NBER Working Paper 26803.

Johnson, Robert C., "Trade in Intermediate Inputs and Business Cycle Comovement," American Economic Journal: Macroeconomics, October 2014, 6 (4), 39-83.

- and Guillermo Noguera, "Accounting for intermediates: Production sharing and trade in value added," Journal of International Economics, 2012, 86 (2), 224 - 236.

- and _, "A Portrait of Trade in Value-Added over Four Decades," Review of Economics and Statistics, 2017, 99 (5), 896-911. 
Kehoe, Timothy J. and Kim J. Ruhl, "Are Shocks to the Terms of Trade Shocks to Productivity?," Review of Economic Dynamics, October 2008, 11 (4), 804-819.

Kikkawa, Ayumu Ken, Glenn Magerman, and Emmanuel Dhyne, "Imperfect Competition in Firmto-Firm Trade," March 2022. Forthcoming, Journal of the European Economis Association.

Kleinert, Jörn, Julien Martin, and Farid Toubal, "The Few Leading the Many: Foreign Affiliates and Business Cycle Comovement," American Economic Journal: Macroeconomics, October 2015, $7(4), 134-159$.

Kleinman, Benny, Ernest Liu, and Stephen J Redding, "International Friends and Enemies," July 2020. NBER Working Paper 27587.

Koenig, Michael D., Andrei A. Levchenko, Tim Rogers, and Fabrizio Zilibotti, "Aggregate Fluctuations in Adaptive Production Networks," May 2022. Forthcoming, Proceedings of the National Academy of Sciences.

Kydland, Finn E. and Edward C. Prescott, "Time to Build and Aggregate Fluctuations," Econometrica, 1982, 50 (6), 1345-1370.

Lim, Kevin, "Endogenous Production Networks and the Business Cycle," September 2018. Mimeo, University of Toronto.

Long, John B. and Charles I. Plosser, "Real Business Cycles," Journal of Political Economy, February 1983, $91(1), 39-69$.

Melitz, Marc J., "The Impact of Trade on Intra-Industry Reallocations and Aggregate Industry Productivity," Econometrica, November 2003, 71 (6), 1695-1725.

Obstfeld, Maurice and Kenneth Rogoff, "Exchange Rate Dynamics Redux," The Journal of Political Economy, 1995, 103, 624-60.

Taschereau-Dumouchel, Mathieu, "Cascades and Fluctuations in an Economy with an Endogenous Production Network," July 2019. Mimeo, Cornell.

Timmer, Marcel P., Erik Dietzenbacher, Bart Los, Robert Stehrer, and Gaaitzen J. de Vries, "An Illustrated User Guide to the World Input-Output Database: the Case of Global Automotive Production," Review of International Economics, August 2015, 23 (3), 575-605.

Yi, Kei-Mu, "Can Vertical Specialization Explain the Growth of World Trade?," Journal of Political Economy, February 2003, 111 (1), 52-102. 


\section{ONLINE APPENDIX \\ (NOT FOR PUBLICATION)}




\section{Appendix A Data and Reduced-Form Results}

\section{A.1 Harmonizing French Firm-Level Data with Global Sectoral Data}

The firm's sector in the French data is reported in the Nomenclature d'Activités Françaises classification, which we convert into the 35 sectors of the WIOD nomenclature. Note that the balance-sheet data do not cover Financial Activities and Private Households with Employed Persons (sectors J and $\mathrm{P}$ in WIOD), and thus those sectors are dropped from the analysis. We also dropped the "Public Administration" sector (sector L) which represents 23 firms and less than $0.02 \%$ of overall value added in our data.

Data on individual bilateral imports, together with information on each firm's cost structure, are used to recover the firm-specific input shares. Firm-specific labor shares $\pi_{f, n, j}^{l}$ are defined as the ratio of value added over sales, both available in the balance-sheet data. In order to ensure comparability with the rest of the sample, in which labor shares are calibrated using WIOD for each country and sector, the distribution of firm-level labor shares is rescaled sector-by-sector in a way that preserves the heterogeneity but ensures that the weighted average across firms matches the corresponding information in the WIOD. Namely:

$$
\pi_{f, n, j}^{l}=\tilde{\pi}_{f, n, j}^{l} \frac{\pi_{n, j}^{l}}{\tilde{\pi}_{n, j}^{l}} .
$$

In this equation, $\pi_{f, n, j}^{l}$ and $\tilde{\pi}_{f, n, j}^{l}$ are the rescaled and original firm-level coefficients, respectively, and $\pi_{n, j}^{l}$ is the sectoral counterpart recovered from the WIOD data. Finally, $\tilde{\pi}_{n, j}^{l}$ is a weighted average of the original firm-level coefficients, where each firm is weighted according to its share $\omega_{f, n, j}^{S}$ in sectoral sales: $\tilde{\pi}_{n, j}^{l}=\sum_{f \in(n, j)} \omega_{f, n, j}^{S} \tilde{\pi}_{f, n, j}^{l} \cdot{ }^{19}$

Figure A1 displays the cumulative distribution of labor shares, distinguishing between tradable and non-tradable sectors. The solid (red) line correspond to the unweighted distributions and the (blue) circles to the weighted ones. These distributions show a high degree of heterogeneity across firms, both within and across broad sectors. In traded good sectors, large firms tend to be less labor intensive, although the pattern is not systematic in all individual sectors and is not very strong. On the contrary, large firms in non-traded good sectors are often more labor-intensive than smaller ones. $^{20}$

\footnotetext{
${ }^{19}$ The rescaling procedure implies that some rescaled firm-level coefficients end up lying outside of the range of possible values $([0,1])$. The corresponding coefficients are winsorized at the maximum and minimum values. This affects less than $2 \%$ of the firms in the total sample. The rescaling procedure is applied to all sectors but three, namely Wholesale; Retail, including Motor Vehicles; and Fuel. For these three sectors, the average labor share is low in the French data compared to the WIOD. This comes from the treatment of merchandise, which we categorize as intermediates while WIOD does not. Our approach is consistent with the model in the case of France, where we assume that consumers never interact directly with foreign firms. From that point of view, all merchandise imported from abroad is used as inputs by a French firm which ultimately sells to the final consumer. Because this is all the more important for retailing and wholesaling activities, we decided to keep the distribution of measured $\pi_{f, n, j}^{l}$ unchanged in these sectors.

${ }^{20}$ In the tradable sectors, the correlation between the firm's labor share and its size is on average mildly negative
} 
Table A1. Summary Statistics of Firms, by Sector

\begin{tabular}{|c|c|c|c|}
\hline "WIOD sector & \# firms & Share VA & $\overline{\text { Traded/non-traded }}$ \\
\hline Agriculture & 1,146 & 0.0008 & $\mathrm{~T}$ \\
\hline Mining & 1,047 & 0.0051 & $\mathrm{~T}$ \\
\hline Food products & 12,257 & 0.0434 & $\mathrm{~T}$ \\
\hline Textile products & 4,143 & 0.0102 & $\mathrm{~T}$ \\
\hline Leather \& Footwear & 598 & 0.0021 & $\mathrm{~T}$ \\
\hline Wood products & 2,933 & 0.0050 & $\mathrm{~T}$ \\
\hline Paper products & 6,339 & 0.0142 & $\mathrm{~T}$ \\
\hline Refined petroleum & 47 & 0.0080 & $\mathrm{~T}$ \\
\hline Chemical products & 2,231 & 0.0437 & $\mathrm{~T}$ \\
\hline Rubber and Plastics & 3,199 & 0.0190 & $\mathrm{~T}$ \\
\hline Other Non-Metallic Mineral & 2,812 & 0.0150 & $\mathrm{~T}$ \\
\hline Basic and Fabricated Metals & 13,061 & 0.0400 & $\mathrm{~T}$ \\
\hline Machinery. Nec & 4,525 & 0.0220 & $\mathrm{~T}$ \\
\hline Electrical Equipment & 3,444 & 0.0333 & $\mathrm{~T}$ \\
\hline Transport Equipment & 1,546 & 0.0287 & $\mathrm{~T}$ \\
\hline Manufacturing. Nec & 12,147 & 0.0226 & $\mathrm{~T}$ \\
\hline Electricity. Gas and Water Supply & 2,250 & 0.0436 & NT \\
\hline Construction & 61,761 & 0.0730 & NT \\
\hline Retailing Motor Vehicles & 26,150 & 0.0348 & NT \\
\hline Wholesale trade & 54,899 & 0.1045 & NT \\
\hline Retail trade & 83,606 & 0.0903 & NT \\
\hline Hotels and Restaurants & 32,412 & 0.0295 & NT \\
\hline Inland Transport & 10,101 & 0.0422 & NT \\
\hline Water Transport & 195 & 0.0021 & NT \\
\hline Air Transport & 70 & 0.0091 & NT \\
\hline Other Transport Activities & 2,433 & 0.0227 & NT \\
\hline Post and Telecommunications & 10,192 & 0.1049 & NT \\
\hline Real Estate Activities & 8,596 & 0.0189 & NT \\
\hline Business Activities & 28,675 & 0.0772 & $\mathrm{NT}$ \\
\hline Education & 2,018 & 0.0025 & NT \\
\hline Health and Social Work & 6,310 & 0.0187 & NT \\
\hline Other Personal Services & 16,514 & 0.0128 & NT \\
\hline Total & 417,657 & 1.0000 & \\
\hline
\end{tabular}

Notes: This table reports summary statistics on the numbers of firms and shares of aggregate value added by WIOD sector. The data are from INSEE-Ficus/Fare and correspond to year 2005.

Total input usage at the firm level equals one minus the labor share (in our setting "labor" stands for the composite of primary factors). We further disaggregate total input usage across at -0.05 , ranging between -0.25 (Coke, Refined Petroleum and Nuclear Fuel) and 0.09 (Wood Products). In the non-tradable sectors, it is on average positive but quite close to zero at 0.02 , ranging from -0.9 in Water Transport to 0.12 in Real Estate Activities. 
Figure A1. Distribution of Labor Shares Across French Firms

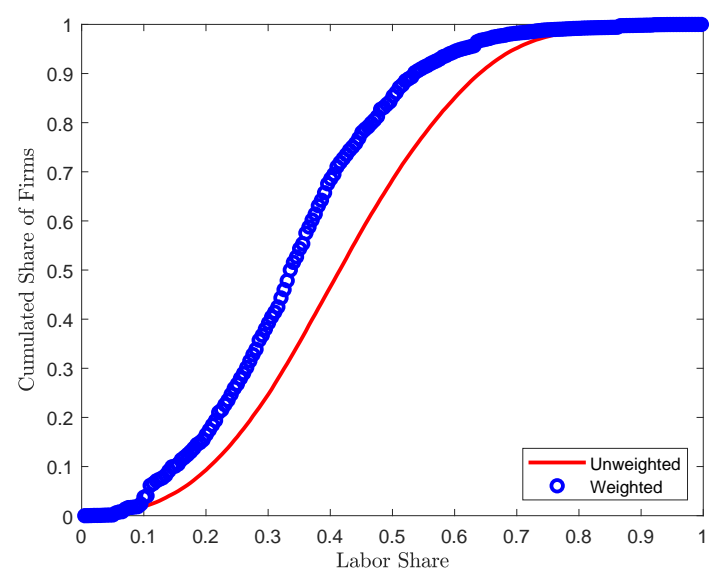

(a) Tradable Sectors

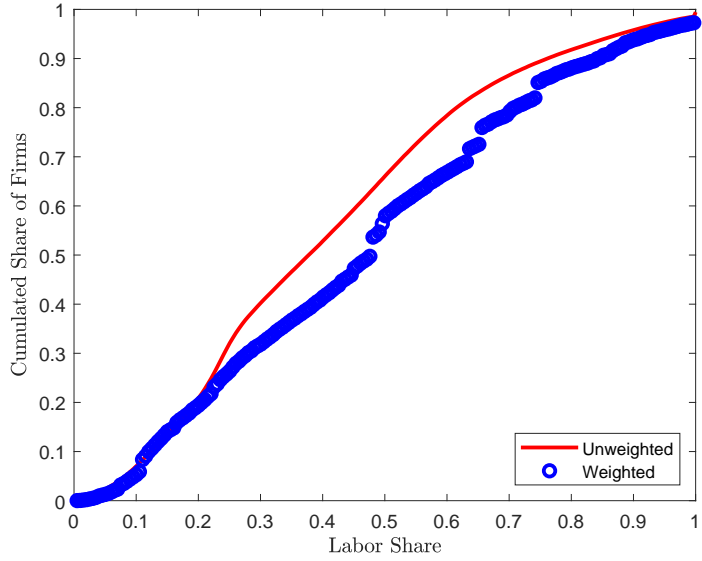

(b) Non-tradable Sectors

Notes: This figure plots the cumulative distributions of firm-level labor shares $\left(\pi_{f, n, j}^{l}\right)$, in tradable and in nontradable sectors. The solid (red) lines correspond to the unweighted distribution and the (blue) circles to the weighted distribution, where firms' weights are defined according to their share in aggregate value added. Calculated from French balance-sheet data together with the WIOD information on sectoral labor shares, for 2005.

sectors and source countries using the information on imports, by product. This allows us to recover the $\pi_{f, m n, i j}^{M}$ coefficients for $n=$ France. While in principle straightforward, calibrating these parameters entails two key difficulties: i) it requires the use of two sources of firm-level data, which raises concerns regarding comparability; and ii) not all of these coefficients can be recovered from the firm-level data. In particular, we do not have detailed information on inputs purchased domestically and thus need to infer their sectoral breakdown using (more aggregated) information from WIOD. We proceed as follows.

For each sector $i$ among the subset of tradable sectors and each source country $m \neq n$, we first compute the share of bilateral imports of goods produced by country $m$, sector $i$ in the firm's total input expenses. ${ }^{21}$ Since this ratio uses data collected from two databases, the overall import share obtained from the summation of these $\pi_{f, m n, i j}^{M}$ coefficients over all tradable sectors and foreign countries is larger than one in some cases (for less than $1.5 \%$ of firms). Whenever this happens, the import share is winsorized to one and the bilateral sectoral coefficients rescaled accordingly.

Beyond comparability issues between the two firm-level sources, the introduction of these firmlevel import shares into the broader multi-country model also means we must ensure consistency

\footnotetext{
${ }^{21}$ This requires the conversion of product-level import data expressed in the highly disaggregated Harmonized System into broader sectoral categories. Since the customs data do not allow us to distinguish between the import of intermediates and merchandise (goods that are not further processed before being sold by the firm), we measure the firm's input expenses accordingly as the sum of raw materials and merchandise purchases (taking into account changes in inventories). See Blaum et al. (2018) for a similar treatment of the data.
} 
with the sectoral coefficients in the global data. As we did with the labor shares, this implies rescaling the overall distribution of firm-level coefficients to the mean observed in the WIOD data:

$$
\pi_{f, m n, i j}^{M}=\tilde{\pi}_{f, m n, i j}^{M} \frac{\pi_{m n, i j}^{M}}{\tilde{\pi}_{m n, i j}^{M}},
$$

where $\pi_{f, m n, i j}^{M}$ and $\tilde{\pi}_{f, m n, i j}^{M}$ denote the rescaled and original firm-level coefficients, respectively, $\pi_{m n, i j}^{M}$ is the sectoral counterpart measured with the WIOD data, and $\tilde{\pi}_{m n, i j}^{M}$ is the weighted average of the firm-level original coefficients, where each firm is weighted according to its share $\omega_{f, n, j}^{M}$ in sectoral input purchases: $\tilde{\pi}_{m n, i j}^{M}=\sum_{f \in(n, j)} \omega_{f, n, j}^{M} \pi_{f, m n, i j}^{M}$. The normalization preserves as much heterogeneity across firms as possible, while avoiding overestimating the international transmission of shocks through foreign input purchases via an exaggeration of the degree to which French firms actually rely on foreign inputs. From that point of view, our calibration is conservative.

By definition, the remaining input purchases, those not sourced abroad, include tradable goods purchased in France and all expenses on non-tradable inputs. While we do not have any information on how these domestic expenses are spread across sectors, we can recover the firm-level share of individual input purchases as $\sum_{i} \pi_{f, n n, i j}^{M}=1-\sum_{m \neq n} \sum_{i \in T} \pi_{f, m n, i j}^{M}$. This domestic input share is then assigned to domestic input sectors using information in the WIOD: ${ }^{22}$

$$
\pi_{f, n n, i j}^{M}=\frac{\pi_{n n, i j}^{M}}{\sum_{i} \pi_{n n, i j}^{M}} \times \sum_{i} \pi_{f, n n, i j}^{M} .
$$

We have tested an alternative calibration strategy in which the input coefficients for non-traded sectors are all set exactly to their values in the WIOD. The remaining (homogeneous) share in input purchases is then spread across tradable sectors and countries using the bilateral import shares available at the firm level. The residual which corresponds to tradable inputs purchased domestically is spread across sectors using the WIOD coefficients. Note that this strategy tends to underestimate the share of tradable goods that are purchased domestically, i.e., it overestimates the participation of French firms to foreign input markets. For this reason, we have chosen to use the more conservative strategy described above as our benchmark.

\section{A.2 Other Outcome Variables, Controls, and Trade Participation}

Columns 1, 2, and 3 of Table A2 contain results for: (i) the labor costs, (ii) the materials spending, and (iii) the firm imported inputs. Just like total value added, the components of labor costs and materials spending are more sensitive to foreign GDP for larger firms. For real imported inputs the

\footnotetext{
${ }^{22}$ Our definition of non-tradable (NT) sectors is somewhat unconventional since we de facto exclude from the tradable sector all services that are potentially traded but that we do not observe in the customs data. As a consequence, some of our NT sectors might display strictly positive foreign input shares in WIOD, i.e. $\pi_{m n, i j}^{M} \neq 0$ for $j \in N T$. We adjust the WIOD data to make them consistent with our definition of non-tradable sectors by allocating all purchases from a NT sector to the same French sector, i.e.: $\pi_{n n, i j}^{M}=\sum_{m} \pi_{m n, i j}^{M} \quad$ and $\quad \pi_{m n, i j}^{M}=0, \forall i \in N T$. We apply the same adjustment to the other countries in the sample, to ensure comparability.
} 
coefficient is positive but not statistically significant. At the same time, however, the sample size falls by more than four-fifths. These firms are already larger than the rest, and selected precisely on their importing status. Evidently, within this subsample the variation in size is not informative about the differential sensitivity to foreign shocks, perhaps because all importing firms are about equally sensitive to foreign GDP growth.

Table A3 performs a set of exercises that includes firm participation in international trade. Here the goal of the exercise is more subtle. Our model rationalizes the size-sensitivity to foreign shocks relationship through differential participation in import and export markets. Thus, to be consistent with the theory, we would like to see that the relationship between firm size and the sensitivity to foreign GDP growth becomes substantially attenuated once we control for trade linkages.

We pursue two strategies. In the first, we use im/exporting status as a control variable, by including dummies for im/exporting status, and their interactions with foreign GDP growth alongside our regressor of interest, which is the firm size-foreign GDP growth interaction. Column 1 of Table A3 reports the results. As hoped, the coefficient on the size-foreign GDP interaction falls by $40 \%$ in magnitude, and its significance level drops to $10 \%$.

Because the regression in equation (6) is run at the firm-time level, it is not an ideal setting to explore the impact of importing and exporting on the comovement of firms with foreign countries, because both firm imports and exports are source/destination specific, and regression (6) does not include the source/destination dimension. The overall im/exporting status may not be a good control because different firms trade with different countries, and they should be more sensitive to GDP growth primarily of the countries with which they actually trade. To improve the quality of these controls, we construct alternative measures of sensitivity of im/exporters to foreign GDP growth, by picking out the GDP growth of only countries with which a firm trades:

$$
d \ln Y_{f, W, t}^{I M}=\sum_{m} I M_{f, m, j, t-1} d \ln Y_{m, t},
$$

where $d \ln Y_{m, t}$ is GDP growth in country $m$, and $I M_{f, m, j, t-1}$ is the dummy that takes a value of 1 if firm $f$ imports from country $m$ in the initial period. We define the exporter-specific foreign growth in the same way:

$$
d \ln Y_{f, W, t}^{E X}=\sum_{m} E X_{f, m, j, t-1} d \ln Y_{m, t},
$$

where $E X_{f, m, j, t-1}$ is a dummy for whether firm $f$ exported to $m$ in the initial period.

Column 2 of Table A3 reports the results. The original size-foreign GDP growth interaction coefficient falls further and becomes insignificant. This approach also leads to more sensible results when it comes to im/exporting status and sensitivity to foreign growth. The coefficients on both $d \ln Y_{f, W, t}^{I M}$ and $d \ln Y_{f, W, t}^{E X}$ are strongly significant and positive.

An alternative approach is to estimate separate size-foreign growth interaction coefficients by 
trade status. That is we run:

$$
d \ln Y_{f, n, j, t}=\beta_{0} d \ln Y_{W, t}+\sum_{\substack{S=D O M, T R A D E}} \beta_{1, S} \mathbb{1}_{S} \times \ln Y_{f, n, j, t-1} \times d \ln Y_{W, t}+\beta_{2} \ln Y_{f, n, j, t-1}+\boldsymbol{\delta}+\epsilon_{f, t} .
$$

In this specification, firms are split into 2 mutually exclusive categories: purely domestic (neither importer nor exporter), vs. trading. The specification (A.3) then allows these categories to have different sensitivities to foreign GDP growth. Column 3 of Table A3 reports the results. The most important finding is that purely domestic firms do not experience significantly greater sensitivity to foreign GDP growth if they are larger. The sensitivity to firm value added growth to foreign GDP growth is size-dependent only for firms that trade.

All in all, these results support our modeling approach. The baseline specification focuses on the differential sensitivity to foreign GDP growth by firm size because of parsimony and a tight connection to the notion of the granular residual, which is the covariance between firm size and firm-level responses to foreign shocks. Focusing on size provides an especially parsimonious way to summarize all the complexity in the importing and exporting links across firms, sources, and destinations, and connect our results directly to the granularity literature. ${ }^{23}$

In the model, this regularity is captured by the differences in the participation in international trade across firms of different sizes. Controlling for importing and exporting reduces the sizeforeign GDP growth interaction coefficient substantially, and renders it insignificant. Furthermore, the greater sensitivity to foreign GDP growth is not observed for purely domestic firms. Thus, these results support our modeling approach in which international trade is the reason why larger firms are more sensitive to foreign shocks.

Finally, we now include the firm's multinational status and its interaction with world GDP growth as controls. To do this, we merge the Liaisons Financières (LiFi) survey into our data. This survey contains information on which firms in France have foreign affiliates, and which French firms are affiliates of foreign companies. ${ }^{24}$ The information on multinational status is the only dimension of international financial integration at the firm level available to us, but it is an important one (see, e.g., Desai et al., 2004). Column 4 of Table A2 reports the results of controlling for a multinational dummy $\left(M N E_{f, t-1}\right)$ and an interaction of the multinational dummy with foreign GDP growth. Foreign multinationals tend to be less responsive to foreign GDP growth than non-multinationals, though the coefficient is tiny in magnitude. However, even controlling for this effect, the size-growth interaction remains positive and significant, with the same magnitude as the baseline. ${ }^{25}$

\footnotetext{
${ }^{23}$ Since not all firms trade with all countries, an explicitly bilateral approach in which an observation is comovement between firm $f$ and country $m$, is a better way to document that trade linkages create comovement. We pursue a full treatment of the bilateral approach in our 2018 paper (di Giovanni et al., 2018). Indeed, the finding that im/exporting firms are more correlated with foreign GDP is not new. These is an additional reason to focus on size as a single summary firm characteristic in the current paper.

${ }^{24}$ di Giovanni et al. (2018) describes these data in detail.

${ }^{25}$ We obtain a similar coefficient and significance level if we simply drop multinationals from the estimation sample.
} 
Just like with goods trade above, multinational firms are only engaged with a subset of countries. That is, a French multinational company typically has affiliates in a limited number of foreign countries, and a French affiliate of a foreign multinational has its headquarters in a particular foreign country. Thus, we refine the multinational-foreign growth indicators in a way similar to what we did for trade indicators. Namely, for the French headquarters with affiliates abroad, we construct the growth rate of countries where the firm has affiliates:

$$
d \ln Y_{f, W, t}^{A F}=\sum_{m} A F_{f, m, j, t-1} d \ln Y_{m, t}
$$

where $A F_{f, m, j, t-1}$ is the dummy that takes a value of 1 if firm $f$ has an affiliate in $m$. For French affiliates of foreign companies, we use the growth rate of the country in which the parent company is headquartered, $d \ln Y_{f, H Q, t}$. The results are in column 5 of Table A2. After this refinement, both the size and the significance of the size interaction are still essentially at their baseline values and significance levels. 
Table A2. Sensitivity to Foreign GDP Growth by Firm Size: Other Outcomes and Multinational Status

\begin{tabular}{|c|c|c|c|c|c|}
\hline Dep. Var.: & $\begin{array}{c}(1) \\
\text { Labor costs }\end{array}$ & $\begin{array}{c}(2) \\
\text { Input costs }\end{array}$ & $\begin{array}{c}(3) \\
\text { Imported input costs }\end{array}$ & $\begin{array}{c}(4) \\
\text { Value added }\end{array}$ & $\begin{array}{c}(5) \\
\text { Value added }\end{array}$ \\
\hline $\ln Y_{f, m, j, t-1} \times d \ln Y_{W, t}$ & $\begin{array}{l}0.095^{a} \\
(0.021)\end{array}$ & $\begin{array}{l}0.352^{a} \\
(0.032)\end{array}$ & $\begin{array}{c}0.406 \\
(0.621)\end{array}$ & $\begin{array}{l}0.108^{a} \\
(0.030)\end{array}$ & $\begin{array}{c}0.108^{a} \\
(0.030)\end{array}$ \\
\hline $\ln Y_{f, m, j, t-1}$ & $\begin{array}{r}-0.006^{a} \\
(0.001)\end{array}$ & $\begin{array}{r}-0.015^{a} \\
(0.001)\end{array}$ & $\begin{array}{r}-0.076^{a} \\
(0.019)\end{array}$ & $\begin{array}{r}-0.021^{a} \\
(0.001)\end{array}$ & $\begin{array}{r}-0.021^{a} \\
(0.001)\end{array}$ \\
\hline$M N E_{f, t-1}$ & & & & $\begin{array}{l}0.089^{a} \\
(0.011)\end{array}$ & \\
\hline$M N E_{f, t-1} \times d \ln Y_{W, t}$ & & & & $\begin{array}{l}-0.005^{a} \\
(0.001)\end{array}$ & \\
\hline$A F_{f, t-1}$ & & & & & $\begin{array}{l}0.050^{a} \\
(0.005)\end{array}$ \\
\hline$H Q_{f, t-1}$ & & & & & $\begin{array}{l}0.049^{a} \\
(0.002)\end{array}$ \\
\hline$d \ln Y_{f, W, t}^{A F}$ & & & & & $\begin{array}{r}-0.594^{a} \\
(0.065)\end{array}$ \\
\hline$d \ln Y_{f, W, t}^{H Q}$ & & & & & $\begin{array}{l}0.504^{a} \\
(0.081)\end{array}$ \\
\hline Observations & $1,491,961$ & $1,521,905$ & 274,167 & $1,518,264$ & $1,518,264$ \\
\hline \# years & 11 & 11 & 11 & 11 & 11 \\
\hline \# firms & 136,478 & 138,355 & 39,974 & 138,024 & 138,024 \\
\hline Adjusted $R^{2}$ & 0.010 & 0.016 & 0.007 & 0.020 & 0.020 \\
\hline
\end{tabular}

Notes: Columns 1, 2, and 3 report the estimates of equation (6), with log changes in labor costs, materials costs, and imported input costs as dependent variables. Column 4 controls for the firm's multinational status, with the dummy variable $M N E_{f, t-1}$ taking on the values of 1 if the firm is part of either a French of a foreign multinational. Column 5 separates French headquarters with affiliates abroad $\left(A F_{f, t-1}\right)$, and firms that are affiliates of a foreign firm $\left(H Q_{f, t-1}\right)$, as well as the the differential effect of foreign growth by host-specific multinational status as in (A.4). $d \ln Y_{f, H Q, t}$ is the GDP growth rate of the country in which the parent of firm $f$ is headquartered. Standard errors clustered at the firm level in parentheses with ${ }^{a},{ }^{b}$ and ${ }^{c}$ denoting coefficients significantly different from zero at the 1,5 and $10 \%$ levels, respectively. 
Table A3. Sensitivity to Foreign GDP Growth by Firm Size and Trade Status

\begin{tabular}{|c|c|c|c|}
\hline Dep. Var.: $d \ln Y_{f, m, j, t}$ & (1) & $(2)$ & $(3)$ \\
\hline $\ln Y_{f, m, j, t-1} \times d \ln Y_{W, t}$ & $\begin{array}{c}0.060^{c} \\
(0.034)\end{array}$ & $\begin{array}{c}0.049 \\
(0.030)\end{array}$ & \\
\hline$I M_{f, t-1} \times d \ln Y_{W, t}$ & $\begin{array}{c}0.040 \\
(0.104)\end{array}$ & & \\
\hline$E X_{f, t-1} \times d \ln Y_{W, t}$ & $\begin{array}{c}0.522^{a} \\
(0.103)\end{array}$ & & \\
\hline$d \ln Y_{f, W, t}^{I M}$ & & $\begin{array}{l}0.059^{a} \\
(0.005)\end{array}$ & \\
\hline$d \ln Y_{f, W, t}^{E X}$ & & $\begin{array}{l}0.032^{a} \\
(0.003)\end{array}$ & \\
\hline $\ln Y$ & $\begin{array}{r}-0.023^{a} \\
(0.001)\end{array}$ & $\begin{array}{r}-0.024^{a} \\
(0.001)\end{array}$ & \\
\hline$I M_{f, t-1}$ & $\begin{array}{c}0.027^{a} \\
(0.003)\end{array}$ & $\begin{array}{l}0.022^{a} \\
(0.001)\end{array}$ & \\
\hline$E X_{f, t-1}$ & $\begin{array}{l}0.005^{c} \\
(0.003)\end{array}$ & $\begin{array}{l}0.017^{a} \\
(0.001)\end{array}$ & \\
\hline$D O M_{f, t-1} \times \ln Y_{f, m, j, t-1} \times d \ln Y_{W, t}$ & & & $\begin{array}{c}0.045 \\
(0.035)\end{array}$ \\
\hline$T R A D E_{f, t-1} \times \ln Y_{f, m, j, t-1} \times d \ln Y_{W, t}$ & & & $\begin{array}{l}0.106^{a} \\
(0.030)\end{array}$ \\
\hline$D O M_{f, t-1} \times \ln Y_{f, m, j, t-1}$ & & & $\begin{array}{l}-0.021^{a} \\
(0.001)\end{array}$ \\
\hline$T R A D E_{f, t-1} \times \ln Y_{f, m, j, t-1}$ & & & $\begin{array}{l}-0.023^{a} \\
(0.001)\end{array}$ \\
\hline$D O M_{f, t-1}$ & & & $\begin{array}{l}-0.033^{a} \\
(0.003)\end{array}$ \\
\hline Observations & $1,518,264$ & $1,518,264$ & $1,518,264$ \\
\hline \# years & 11 & 11 & 11 \\
\hline \# firms & 138,024 & 138,024 & 138,024 \\
\hline Adjusted $R^{2}$ & 0.022 & 0.022 & 0.021 \\
\hline
\end{tabular}

Notes: Columns 1 and 2 report the estimates of equation (6), controlling for the differential effect of foreign growth on by import and export status $I M_{f, t-1}$ and $E X_{f, t-1}$, and source/destination-specific trade status as in (A.1) and (A.2). Columns 3 reports the results of estimating equation (A.3). Column 4 reports the results of estimating equation (6), constraining the sample to non-importing and non-exporting firms. Standard errors clustered at the firm level in parentheses with ${ }^{a},{ }^{b}$ and ${ }^{c}$ denoting coefficients significantly different from zero at the 1,5 and $10 \%$ levels, respectively. 


\section{Appendix B Theory and Quantification}

\section{B.1 The GDP Deflator Construction in the Model}

This Appendix describes how we replicate the procedures used by the system of national accounts to compute changes in real GDP and the GDP deflator. The GDP deflator is an implicit deflator that is defined as the ratio of nominal and real GDP changes. In turn, the real GDP is computed using the "double deflation" method that records output net of inputs when both are evaluated at base prices. Specifically, define real GDP, evaluated at base prices (prices at -1 ) by:

$$
Y_{n}=\sum_{j=1}^{\mathcal{J}}\left(P_{n, j,-1} Q_{n, j}-P_{n, j,-1}^{M} M_{n, j}\right),
$$

where $Q_{n, j}$ is the gross physical output in sector $j, M_{n, j}$ is the physical use of inputs in the sector, $P_{n, j,-1}$ is the gross output base price, and $P_{n, j,-1}^{M}$ is the base price of inputs in that sector.

Denote by a "hat" a gross proportional change in a variable relative to its base value: $\widehat{x} \equiv x / x_{-1}$. The gross change in real GDP is then:

$$
\widehat{Y}_{n}=\sum_{j=1}^{\mathcal{J}} \omega_{n, j,-1}^{D}\left(\widehat{Q}_{n, j}-\pi_{n, j,-1}^{M} \widehat{M}_{n, j}\right),
$$

where $\omega_{n, j,-1}^{D} \equiv \frac{P_{n, j,-1} Q_{n, j,-1}}{Y_{n,-1}}$ is the base period Domar weight of sector $j$, that is, the ratio of the sector's gross sales to aggregate value added, and $\pi_{n, j,-1}^{M}$ is the base period sector-level share of input spending in gross output. Since $\omega_{n, j,-1}^{D}$ and $\pi_{n, j,-1}^{M}$ are both nominal beginning-of-period values, they are easily constructable from data.

To measure changes in physical quantities $\widehat{Q}_{n, j}$ and $\widehat{M}_{n, j}$, in practice national statistical agencies measure sectoral nominal gross sales and PPIs, and deflate the gross sales changes by PPI changes. That is, the pieces of data at the disposal of the statistical agencies are: nominal output in a sector, call it $P_{n, j} Q_{n, j}$, and a change in PPI, call it $\widehat{P}_{n, j}$. Then:

$$
\widehat{Q}_{n, j}=\frac{1}{\widehat{P}_{n, j}} \times \frac{P_{n, j} Q_{n, j}}{P_{n, j,-1} Q_{n, j,-1}} .
$$

For inputs, the mechanics are the same, but we have to know the change in the input price deflator in every sector, call it $\widehat{P}_{n, j}^{M}$. Then:

$$
\widehat{M}_{n, j}=\frac{1}{\widehat{P}_{n, j}^{M}} \times \frac{P_{n, j}^{M} M_{n, j}}{P_{n, j,-1}^{M} M_{n, j,-1}} .
$$

For the implementation inside our model, it is trivial to compute the sectoral nominal output and 
input spending growth relative to pre-shock values:

$$
\begin{aligned}
\frac{P_{n, j} Q_{n, j}}{P_{n, j,-1} Q_{n, j,-1}} & =\frac{\sum_{m} \sum_{f \in \Omega_{n m, j}} X_{f, n m, j}}{\sum_{m} \sum_{f \in \Omega_{n m, j}} X_{f, n m, j,-1}} \\
\frac{P_{n, j}^{M} M_{n, j}}{P_{n, j,-1}^{M} M_{n, j,-1}} & =\frac{\sum_{m} \sum_{f \in \Omega_{n m, j}}\left(1-\pi_{f, n, j}^{l}\right) X_{f, n m, j}}{\sum_{m} \sum_{f \in \Omega_{n m, j}}\left(1-\pi_{f, n, j,-1}^{l}\right) X_{f, n m, j,-1}} .
\end{aligned}
$$

For price indices, in best practice of the statistical agencies, $\widehat{P}_{n, j}$ is just the PPI change. There is some heterogeneity across countries in whether the PPI includes export prices or not. For us, PPI will include exports, and will be computed as

$$
\widehat{P}_{n, j}=\sum_{m} \sum_{f \in \Omega_{n m, j}} \omega_{f, n m, j,-1}^{j} \widehat{p}_{f, n m, j}
$$

where $\omega_{f, n m, j,-1}^{j} \equiv \frac{X_{f, n m, j,-1}}{\sum_{m} \sum_{f \in \Omega_{n m, j}} X_{f, n m, j,-1}}$ is the gross output weight of the firm's sales to $m$ in sector $j$ sales. Note that this is more comprehensive than what is actually done in practice, as the PPI is a survey that catches the minority of firms, and thus implementing (B.2) amounts to using more data than the statistical agencies do.

To construct the input price deflator $\widehat{P}_{n, j}^{M}$, the statistical agencies use the PPI and the IO tables. We mimic this procedure by computing the input-share weighted change in input prices, where we use the PPI for the domestic inputs, and the foreign sectoral price changes for foreign inputs. The important thing is that we carry this out at the sector level, without using any firm-level information:

$$
\widehat{P}_{n, j}^{M}=\sum_{i} \sum_{k} \pi_{k n, i j,-1}^{M} \widehat{P}_{k, i}
$$

The $\pi_{k n, i j,-1}^{M}$ 's are the input shares coming from the WIOD. For the domestic components of the right-hand side of this expression, the $\widehat{P}_{k, i}$ are just the PPI's from (B.2). For the foreign components, we assume that the foreign import prices are measured correctly, and use the import price indices from a particular country and sector, called $\widehat{P}_{k n, j}$ in the main text.

Now we have all the ingredients to compute the real GDP change (B.1). Since the GDP deflator is defined implicitly as the ratio between the nominal and real GDP change, we also need to compute the nominal GDP change. The nominal GDP change is a weighted sum of all firms' nominal value added changes. In particular, in our framework nominal value added associated with firm $f$ 's sales to market $m$ is a constant fraction of its sales there:

$$
Y_{f, n m, j}^{N O M}=\frac{1+\pi_{f, n, j}^{l}(\rho-1)}{\rho} X_{f, n m, j},
$$

and thus total firm value added is given by:

$$
Y_{f, n, j}^{N O M}=\frac{1+\pi_{f, n, j}^{l}(\rho-1)}{\rho} \sum_{m} X_{f, n m, j} .
$$


Nominal GDP is simply the sum over all firm-level value added, as in (1). The change in GDP is:

$$
\widehat{Y}_{n}^{N O M}=\sum_{f} \sum_{m} \omega_{f, n, j,-1} s_{f, n m, j,-1} \widehat{X}_{f, n m, j}
$$

where, as in Section 2, $\omega_{f, n, j,-1}$ is the pre-shock share of firm $f$ 's value added in total GDP, and $s_{f, n m, j,-1}$ is the pre-shock share of sales to $m$ in firm $f$ 's total gross sales.

Finally, the GDP deflator is defined implicitly as the ratio of nominal and real GDP:

$$
\widehat{P}_{n}^{G D P}=\frac{\widehat{Y}_{n}^{N O M}}{\widehat{Y}_{n}} .
$$

\section{B.2 A Shock Formulation of the Model}

To perform counterfactuals that simulate the impact of foreign shocks on domestic firms and the aggregate economy, we follow the approach of Dekle et al. (2008) and express the equilibrium conditions in terms of gross changes $\widehat{x}=x / x_{-1}$ in endogenous variables, to be solved for as a function of shocks expressed in gross changes, and the pre-shock ("-1") observables. Starting with (10), we write it as a function of observed expenditure shares:

$$
\begin{aligned}
X_{m n, j}= & \pi_{m n, j}^{c} \pi_{n, j}^{c}\left[w_{n}\left(\frac{1}{\psi_{0}} \frac{w_{n}}{P_{n}}\right)^{\frac{1}{\psi-1}} \bar{L}_{n}+\Pi_{n}+D_{n}\right] \\
& +\sum_{i} \frac{\rho-1}{\rho} \sum_{f \in i}\left(1-\pi_{f, n, i}^{l}\right) \pi_{f, m n, j i}^{M} \sum_{k} \pi_{f, n k, i} X_{n k, i}
\end{aligned}
$$

where $\pi_{m n, j}^{c}$ is the share of final consumption spending on goods from $m$ in the total consumption spending on goods in sector $j$, country $n, \pi_{n, j}^{c}=\vartheta_{n, j}$ is simply the share of sector $j$ in total final consumption spending, and $\pi_{f, n k, i}$ is the share of firm $f$ in the total exports from country $n$ to country $k$ in sector $i$. All of these $\pi$ 's are observable when $n=$ France. $\pi_{m n, j}^{c}$ and $\pi_{n, j}^{c}$ are observable in WIOD. $\pi_{f, n k, i}$ when neither $n$ nor $k$ are France is not observable, so would require an assumption on which firms use imported intermediates. Since we do not have firm-level information on other countries, we assume that in those countries there is a representative firm in each sector. Writing out the shares:

$$
\begin{aligned}
\pi_{n, j}^{c} & =\vartheta_{n, j}, \\
\pi_{m n, j}^{c} & =\frac{\mu_{m n, j} P_{m n, j}^{1-\sigma}}{\sum_{k} \mu_{k n, j} P_{k n, j}^{1-\sigma}}, \\
\pi_{f, n k, i} & =\frac{\xi_{f, n k, i}\left(\frac{\rho}{\rho-1} \frac{\tau_{n k, i} b_{f, n, i}}{a_{f}}\right)^{1-\rho}}{P_{n k, i}^{1-\rho}} .
\end{aligned}
$$


Then, in proportional changes relative to pre-shock values, (B.4) can be written as:

$$
\begin{aligned}
\widehat{X}_{m n, j} X_{m n, j,-1}= & \pi_{m n, j}^{c} \pi_{n, j}^{c}\left[\widehat{w}_{n}\left(\frac{\widehat{w}_{n}}{\widehat{P}_{n}}\right)^{\frac{1}{\psi-1}} s_{n,-1}^{L}+\widehat{\Pi}_{n} s_{n,-1}^{\Pi}+\widehat{D}_{n} s_{n,-1}^{D}\right] P_{n,-1} C_{n,-1} \\
& +\sum_{i} \frac{\rho-1}{\rho} \sum_{f \in i}\left(1-\pi_{f, n, i}^{l}\right) \pi_{f, m n, j i}^{M} \sum_{k} \pi_{f, n k, i} \widehat{X}_{n k, i} X_{n k, i,-1},
\end{aligned}
$$

where $s_{n,-1}^{L}$ is the pre-shock share of labor (more generally factor payments) in the total final consumption expenditure, and the same for $s_{n,-1}^{\Pi}$ and $s_{n,-1}^{D}$.

Equation (12) is expressed in changes as:

$$
\sum_{j} \sum_{f \in j} \sum_{k} \frac{\rho-1}{\rho} \pi_{f, n, j,-1}^{l} \pi_{f, n k, j,-1} X_{n k, j,-1}\left[\widehat{\pi}_{f, n, j}^{l} \widehat{\pi}_{f, n k, j} \widehat{X}_{n k, j}-\widehat{w}_{n}^{\frac{\bar{\psi}}{\bar{\psi}-1}} \widehat{P}_{n}^{\frac{1}{1-\bar{\psi}}}\right]=0 .
$$

The prices (11) are expressed in changes as:

$$
\begin{aligned}
\widehat{P}_{m n, j} & =\left[\sum_{f \in \Omega_{m n, j}} \pi_{f, m n, j,-1} \widehat{\xi}_{f, m n, j}\left(\widehat{b}_{f, m, j} \widehat{a}_{f}^{-1}\right)^{1-\rho}\right]^{\frac{1}{1-\rho}}, \\
\widehat{P}_{n, j} & =\left[\sum_{m} \widehat{P}_{m n, j}^{1-\sigma} \pi_{m n, j,-1}^{c}\right]^{\frac{1}{1-\sigma}}, \\
\widehat{P}_{n} & =\prod_{j} \widehat{P}_{n, j}^{\vartheta_{n, j}} .
\end{aligned}
$$

Finally, the equations above require knowing post-shock $\pi$ 's. These can be expressed as:

$$
\begin{gathered}
\pi_{m n, j}^{c}=\frac{\widehat{P}_{m n, j}^{1-\sigma} \pi_{m n, j,-1}^{c}}{\sum_{k} \widehat{P}_{k n, j}^{1-\sigma} \pi_{k n, j,-1}^{c}}, \\
\pi_{f, n k, j}=\frac{\widehat{\xi}_{f, n k, j}\left(\widehat{b}_{f, n, j} \widehat{a}_{f}^{-1}\right)^{1-\rho} \pi_{f, n k, j,-1}}{\sum_{g \in \Omega_{n k, j}} \widehat{\xi}_{g, n k, j}\left(\widehat{b}_{g, n, j} \widehat{a}_{g}^{-1}\right)^{1-\rho} \pi_{g, n k, j,-1}}, \\
\widehat{b}_{f, m, j}=\left[\pi_{f, m, j,-1}^{l} \widehat{w}_{m}^{1-\phi}+\left(1-\pi_{f, m, j,-1}^{l}\right)\left(\widehat{P}_{f, m, j}^{M}\right)^{1-\phi}\right]^{\frac{1}{1-\phi}}, \\
\pi_{f, m, j}^{l}=\frac{\left[\sum_{i}^{M} \sum_{k} \pi_{f, k m, i j,-1}^{M} \widehat{P}_{k m, i}^{1-\eta}\right]^{\frac{1}{1-\eta}},}{\pi_{f, m, j,-1}^{l} \widehat{w}_{m}^{1-\phi}+\left(1-\pi_{f, m, j,-1}^{l}\right)\left(\widehat{P}_{f, m, j}^{M}\right)^{1-\phi}}, \\
\pi_{f, k m, i j}^{M}=\frac{\pi_{f, k m, i j,-1}^{M} \widehat{P}_{k m, i}^{1-\eta}}{\sum_{i} \sum_{n} \pi_{f, n m, i j,-1}^{M} \widehat{P}_{n m, i}^{1-\eta}} .
\end{gathered}
$$




\section{B.2.1 Model Solution and Calibration}

The model implementation involves solving equations (B.5)-(B.15). In particular, we solve for the following equilibrium variables:

1. Changes in trade values $\widehat{X}_{m n, j} \forall m, n, j$;

2. Changes in wages $\widehat{w}_{n} \forall n$;

3. Changes in the price indices $\widehat{P}_{n} \forall n, \widehat{P}_{n, j} \forall n, j, \widehat{P}_{m n, j} \forall m, n, j$;

4. Post-shock trade shares $\pi_{m n, j}^{c} \forall m, n, j, \pi_{f, n k, j} \forall k, n, j, f, \pi_{f, n, j}^{l} \forall n, j, f, \pi_{f, m n, i j}^{M} \forall n, m, i, j, f$. We further require several pre-shock data series, either at the firm or sector level. Specifically, we require information on:

1. Gross sales $X_{m n, j,-1} \forall m, n, j$;

2. Final consumption shares within a sector across sources $\pi_{m n, j,-1}^{c} \forall m, n, j$;

3. Firm-level within sector, within-destination trade shares $\pi_{f, n k, j,-1} \forall k, n, j, f$;

4. Final consumption spending $P_{n,-1} C_{n,-1}$;

5. Shares of labor (factor) income, pure profits, and deficits in final consumption spending $s_{n,-1}^{L}$, $s_{n,-1}^{\Pi}$ and $s_{n,-1}^{D} \forall n$;

6. Initial input shares $\pi_{f, n, j,-1}^{l} \forall n, j, f, \pi_{f, m n, i j,-1}^{M} \forall m, n, i, j, f$.

The construction of these variables and the relevant data sources are described in Appendix A. The solution of the model further requires setting a small number of parameter values. These are summarized in Table 2.

\section{B.2.2 Satisfying Market Clearing}

In order to proceed correctly with the hat algebra in each sector/country pair, in the pre-period the market clearing condition in levels must be satisfied:

$$
X_{m n, j,-1}=\pi_{m n, j,-1}^{c} \pi_{n, j,-1}^{c} P_{n,-1} C_{n,-1}+\sum_{i} \frac{\rho-1}{\rho} \sum_{f \in i}\left(1-\pi_{f, n, i,-1}^{l}\right) \pi_{f, m n, j i,-1}^{M} \sum_{k} \pi_{f, n k, i,-1} X_{n k, i,-1} .
$$

In the data, this is unlikely to be the case. We therefore adopt the following approach: in each $m n, j$, trivially we can find a wedge $\zeta_{m n, j,-1}$ such that conditional on all the other data, (B.16) does hold with equality:

$X_{m n, j,-1}=\pi_{m n, j,-1}^{c} \pi_{n, j,-1}^{c} P_{n,-1} C_{n,-1}+\sum_{i} \frac{\rho-1}{\rho} \sum_{f \in i}\left(1-\pi_{f, n, i,-1}^{l}\right) \pi_{f, m n, j i,-1}^{M} \sum_{k} \pi_{f, n k, i,-1} X_{n k, i,-1}+\zeta_{m n, j,-1}$. 
Then applying the hat algebra to this equation:

$$
\begin{aligned}
\widehat{X}_{m n, j} X_{m n, j,-1}= & \pi_{m n, j}^{c} \pi_{n, j}^{c}\left[\widehat{w}_{n}\left(\frac{\widehat{w}_{n}}{\widehat{P}_{n}}\right)^{\frac{1}{\psi-1}} s_{n,-1}^{L}+\widehat{\Pi}_{n} s_{n,-1}^{\Pi}+\widehat{D}_{n} s_{n,-1}^{D}\right] P_{n,-1} C_{n,-1} \\
& +\sum_{i} \frac{\rho-1}{\rho} \sum_{f \in i}\left(1-\pi_{f, n, i}^{l}\right) \pi_{f, m n, j i}^{M} \sum_{k} \pi_{f, n k, i} \widehat{X}_{n k, i} X_{n k, i,-1} \\
& +\widehat{\zeta}_{m n, j} \zeta_{m n, j,-1} .
\end{aligned}
$$

Next, we solve the entire model while feeding in a "shock" that eliminates this wedge, namely: $\widehat{\zeta}_{m n, j}=0$. Finding the model solution will give the a set of $\widehat{X}_{m n, j}$ 's that are required to arrive at a set of levels of $X_{m n, j}$ for which the market clearing condition is satisfied with equality for every $m n, j$. Then use these $X_{m n, j}$ as the starting (pre-shock) values for all the real counterfactuals we run. The antecedent of this approach is Costinot and Rodríguez-Clare (2014), who use a similar device to eliminate the trade deficits.

\section{B.3 Simulating Actual Foreign GDP Growth}

In any year in the data, there will be a vector of country-specific productivity shocks. Let $\epsilon_{f, m} \equiv$ $d \ln Y_{f, n}^{F} / d \ln a_{m}$ denote the elasticity of value added of firm $f$ to a productivity shock in country $m$. We obtain these elasticities for every firm in France and every partner country by simulating country-specific aggregate productivity shocks $d \ln a_{m}$ in the baseline model, and recording each firm's responses to it. Firm $f$ 's real value added growth rate following a vector of foreign shocks is

$$
d \ln Y_{f, n}^{F}=\sum_{m} \epsilon_{f, m} d \ln a_{m}
$$

Then the change in French GDP due to a worldwide vector of foreign shocks is simply:

$$
d \ln Y_{n}^{F}=\sum_{f} \omega_{f, n,-1} d \ln Y_{f, n}^{F}
$$

We implement (B.18)-(B.19) in two ways. The first approach feeds the aggregate TFP shocks from the Penn World Tables directly into (B.18) to compute each firm's response to those foreign TFP shocks. The second approach uses actual GDP growth rates. To compute the propagation of foreign GDP growth rates into France, we re-express (B.18) directly in terms of elasticities of French firms to foreign GDP. Specifically, instead of (B.18) we assume that firm growth rate following a country-specific shock is:

$$
d \ln Y_{f, n}^{F}=\sum_{m} \widetilde{\epsilon}_{f, m} d \ln Y_{m}
$$

where $\widetilde{\epsilon}_{f, m} \equiv d \ln Y_{f, n}^{F} / d \ln Y_{m}$ is the elasticity of firm $f$ 's value added growth to country $m$ 's GDP, rather than the TFP shock directly. The $\widetilde{\epsilon}_{f, m}$ 's can be computed by simulating a country-specific shock and tracking the response of both firm $f$ and the foreign country's GDP. Equation (B.20) 
is then combined with (B.19) to compute French GDP growth. Once we simulate the firm and aggregate growth rates due to actual changes in foreign TFP and GDP for a sample of years, we can compute the average-granular residual decomposition (3).

Note that implementing (B.18)-(B.19)-(B.20) amounts to the first-order approach, where firm and aggregate responses are linear functions of the vector of foreign shocks. Huo et al. (2019) analyze the properties of the linear solution in a similar environment, and show that the first-order solution is very close to the exact one.

\section{B.4 Proof of Proposition 1}

Since all firms have the same production function, their initial labor shares $\pi_{n, i,-1}^{l}$ and input shares $\pi_{m n, j i,-1}^{M}$ are identical within a sector. All firms face the same effective intermediate input price change: $\widehat{P}_{f, m, j}^{M}=\widehat{P}_{m, j}^{M} \forall f$ (see (B.13)). Then, it is immediate from (B.14) and (B.15) that the post-shock labor and input shares $\pi_{n, i}^{l}$ and $\pi_{m n, j i}^{M}$ are also identical within a sector. The market clearing condition (B.5) becomes:

$$
\begin{aligned}
\widehat{X}_{m n, j} X_{m n, j,-1}= & \pi_{m n, j}^{c} \pi_{n, j}^{c}\left[\widehat{w}_{n}\left(\frac{\widehat{w}_{n}}{\widehat{P}_{n}}\right)^{\frac{1}{\psi-1}} s_{n,-1}^{L}+\widehat{\Pi}_{n} s_{n,-1}^{\Pi}+\widehat{D}_{n} s_{n,-1}^{D}\right] P_{n,-1} C_{n,-1} \\
& +\sum_{i} \frac{\rho-1}{\rho}\left(1-\pi_{n, i}^{l}\right) \pi_{m n, j i}^{M} \sum_{k} \widehat{X}_{n k, i} X_{n k, i,-1},
\end{aligned}
$$

and thus does not involve $\pi_{f, n k, j}$ 's or $\pi_{f, n k, j,-1}$ 's or any other firm-level objects.

Since all firms face the same input bundle cost change: $\widehat{b}_{f, m, j}=\widehat{b}_{m, j} \forall f$ (see (B.12)), the $\pi_{f, n k, j}$ updating Equation (B.11) becomes:

$$
\begin{aligned}
\pi_{f, n k, j} & =\frac{\widehat{\xi}_{f, n k, j}\left(\widehat{b}_{f, n, j} \widehat{a}_{f}^{-1}\right)^{1-\rho} \pi_{f, n k, j,-1}}{\sum_{g \in \Omega_{n k, j}} \widehat{\xi}_{g, n k, j}\left(\widehat{b}_{g, n, j} \widehat{a}_{g}^{-1}\right)^{1-\rho} \pi_{g, n k, j,-1}} \\
& =\frac{\pi_{f, n k, j,-1}}{\sum_{g \in \Omega_{n k, j}} \pi_{g, n k, j,-1}} \\
& =\pi_{f, n k, j,-1},
\end{aligned}
$$

since taste and productivity shocks are not firm-specific, and the denominator sums to 1 . Thus, sales shares are unchanged following a foreign shock: $\pi_{f, n k, j}=\pi_{f, n k, j,-1} \forall f, k$, or $\widehat{\pi}_{f, n k, j}=1 \forall f, k$.

When labor shares $\pi_{n, i,-1}^{l}$ do not differ across firms, the labor market condition (B.6) also does not require firm-level shares, and simplifies to:

$$
\sum_{j} \sum_{k} \frac{\rho-1}{\rho} \pi_{n, j,-1}^{l} X_{n k, j,-1}\left[\widehat{\pi}_{n, j}^{l} \widehat{X}_{n k, j}-\widehat{w}_{n}^{\frac{\bar{\psi}}{\psi-1}} \widehat{P}_{n}^{\frac{1}{1-\psi}}\right]=0,
$$

which once again is independent of $\pi_{f, n k, j}$ 's or $\pi_{f, n k, j,-1}$ 's. 
Finally, the price equation also has no $\pi_{f, n k, j}$ or $\pi_{f, n k, j,-1}$ terms if taste and productivity shocks are not firm-specific:

$$
\begin{aligned}
\widehat{P}_{m n, j} & =\left[\sum_{f \in \Omega_{m n, j}} \pi_{f, m n, j,-1} \widehat{b}_{m, j}^{1-\rho}\right]^{\frac{1}{1-\rho}} \\
& =\widehat{b}_{m, j}
\end{aligned}
$$

These equations define the equilibrium in changes, and thus $\widehat{X}_{m n, j}$ 's and $\widehat{P}_{m n, j}$ 's can be found without knowing the firm-level market shares $\pi_{f, n k, j}$ 's or $\pi_{f, n k, j,-1}$ 's.

Since markups are constant, all the firm-specific prices change by the same proportional amount: $\widehat{p}_{f, m n, j}=\widehat{p}_{m n, j} \forall f$. Because $\widehat{\pi}_{f, m n, j}=1 \forall f, n$, all nominal sales changes are the same across firms within a sector: $\widehat{X}_{f, m n, j}=\widehat{X}_{m n, j}$. Therefore, none of the steps in constructing real GDP in Appendix B.1 require firm-level sales shares.

\section{B.5 $2 \times 2 \times 2$ Model Calibration}

Top panel of Table A4 reports the input coefficients in the homogeneous firm model. In the homogeneous firm model, $24 \%$ of a Tradable sector firm's total costs (intermediates plus primary factors) are spent on foreign inputs, with the remaining $76 \%$ on domestic intermediates and labor. In the Non-Tradable sector, $8 \%$ of total costs go to pay for foreign inputs. These values correspond to the WIOD data when collapsed to 2 sectors and 2 countries, France and ROW.

The bottom panel of Table A4 reports the input coefficients in the final simulation. In the Tradable sector $47 \%$ of Firm 1's costs are spent on foreign inputs. Across simulations, we keep the sector-level share of spending on imported inputs constant in the Tradable sector at $24 \%$. Thus, Firm 2's share of imported inputs is now 1\% (recall that these firms have the same sales). The same reassignment of import shares occurs in the Non-Tradable sector. 
Table A4. Input Coefficients and Domar Weights in the $2 \times 2 \times 2$ Model

\begin{tabular}{|c|c|c|c|c|}
\hline \multirow{6}{*}{$\begin{array}{l}\text { Share of inputs from: } \\
\text { France } \\
\text { ROW }\end{array}$} & \multicolumn{2}{|c|}{ Tradable } & \multicolumn{2}{|c|}{ Non-Tradable } \\
\hline & Firm 1 & Firm 2 & Firm 1 & Firm 2 \\
\hline & \multicolumn{2}{|c|}{ Homogeneous } & \multicolumn{2}{|c|}{ Input Shares } \\
\hline & & & & \\
\hline & 0.76 & 0.76 & 0.92 & 0.92 \\
\hline & 0.24 & 0.24 & 0.08 & 0.08 \\
\hline \multirow[t]{2}{*}{ Domar weight } & 0.21 & 0.21 & 0.52 & 0.52 \\
\hline & \multicolumn{4}{|c|}{ Heterogeneous Input Shares } \\
\hline $\begin{array}{l}\text { Share of inputs from: } \\
\text { France }\end{array}$ & 0.53 & 0.99 & 0.86 & 0.99 \\
\hline ROW & 0.47 & 0.01 & 0.14 & 0.01 \\
\hline Domar weight & 0.21 & 0.21 & 0.52 & 0.52 \\
\hline
\end{tabular}

Notes: This table reports the firm-specific input coefficients and Domar weights in the simplified $2 \times 2 \times 2$ model. 
Table A5. Responses of French Real GDP to 10\% Foreign Productivity and Demand Shocks, CPI Deflation

\begin{tabular}{|c|c|c|c|c|c|c|}
\hline & $d \ln Y^{F}$ & $\mathcal{E}^{F}$ & $\Gamma^{F}$ & $d \ln Y^{F}$ & $\mathcal{E}^{F}$ & $\Gamma^{F}$ \\
\hline Shock: & \multicolumn{3}{|c|}{ Productivity } & \multicolumn{3}{|c|}{ Demand } \\
\hline $\begin{array}{c}\text { Baseline } \\
\text { Share: }\end{array}$ & 6.38 & $\begin{array}{l}4.24 \\
0.664\end{array}$ & $\begin{array}{l}2.15 \\
0.336\end{array}$ & 0.47 & $\begin{array}{l}0.31 \\
0.649\end{array}$ & $\begin{array}{l}0.16 \\
0.351\end{array}$ \\
\hline $\begin{array}{l}\text { Homogeneous firms } \\
\text { Share: }\end{array}$ & 7.34 & $\begin{array}{l}7.31 \\
0.996\end{array}$ & $\begin{array}{l}0.03 \\
0.004\end{array}$ & 0.53 & $\begin{array}{l}0.51 \\
0.968\end{array}$ & $\begin{array}{l}0.02 \\
0.032\end{array}$ \\
\hline
\end{tabular}

Sector-Level Decomposition

\begin{tabular}{ccccccc} 
& $d \ln Y^{F}$ & $\mathcal{E}_{\mathcal{J}}^{F}$ & $\Gamma_{\mathcal{J}}^{F}$ & $d \ln Y^{F}$ & $\mathcal{E}_{\mathcal{J}}^{F}$ & $\Gamma_{\mathcal{J}}^{F}$ \\
Baseline & 6.38 & 5.72 & 0.66 & 0.47 & 0.72 & -0.25 \\
Share: & & 0.897 & 0.103 & & 1.525 & -0.525 \\
& & & & & & \\
\hline
\end{tabular}

Notes: This table reports the change in French GDP, in percentage points, following a $10 \%$ productivity shock (left panel) or a $10 \%$ foreign demand shock for French goods (right panel) in every other country in the world, in both the baseline model and the alternative model that suppresses firm heterogeneity. The table reports the decomposition of the the GDP change into the unweighted average and granular residual terms as in (3). The real GDP is obtained by deflating by CPI. 
Table A6. Robustness: GDP Responses to a Worldwide Productivity Shock in the Baseline vs. Homogeneous Models

\begin{tabular}{|c|c|c|c|c|c|c|}
\hline \multirow[t]{2}{*}{ Model: } & \multicolumn{3}{|c|}{ Baseline } & \multicolumn{3}{|c|}{ Homogeneous firms } \\
\hline & $d \ln Y^{F}$ & $\mathcal{E}^{F}$ & $\Gamma^{F}$ & $d \ln Y^{F}$ & $\mathcal{E}^{F}$ & $\Gamma^{F}$ \\
\hline Main calibration & 2.77 & 0.70 & 2.07 & 3.39 & 3.36 & 0.03 \\
\hline \multicolumn{7}{|l|}{$\rho:$} \\
\hline high: 5 & 1.73 & -2.26 & 4.00 & 2.98 & 2.90 & 0.08 \\
\hline low: 1.5 & 3.77 & 3.37 & 0.40 & 4.03 & 4.16 & -0.13 \\
\hline \multicolumn{7}{|l|}{ Frisch: } \\
\hline high: 2 & 14.43 & 11.02 & 3.42 & 16.21 & 16.14 & 0.06 \\
\hline low: 0.1 & 0.89 & -0.78 & 1.68 & 1.26 & 1.24 & 0.02 \\
\hline \multicolumn{7}{|l|}{$\eta:$} \\
\hline high: 1.5 & 2.30 & 0.25 & 2.06 & 2.71 & 2.59 & 0.12 \\
\hline low: 0.5 & 3.40 & 1.28 & 2.12 & 4.30 & 4.37 & -0.07 \\
\hline \multicolumn{7}{|l|}{$\phi:$} \\
\hline high: 1.5 & 2.87 & 0.69 & 2.19 & 3.63 & 3.65 & -0.02 \\
\hline low: 0.5 & 2.60 & 0.72 & 1.88 & 3.07 & 2.99 & 0.08 \\
\hline \multicolumn{7}{|l|}{$\sigma:$} \\
\hline high: 3 & 0.56 & -1.23 & 1.79 & 0.92 & 0.76 & 0.15 \\
\hline low: 1.1 & 3.62 & 1.38 & 2.24 & 4.37 & 4.36 & 0.00 \\
\hline Flexible markups & 2.89 & 0.80 & 2.10 & 3.39 & 3.36 & 0.03 \\
\hline $\begin{array}{l}\text { Changing profits in } \\
\text { final demand }\end{array}$ & 3.20 & 1.12 & 2.09 & 3.77 & 3.72 & 0.06 \\
\hline
\end{tabular}

Notes: This table reports the change in French GDP, in percentage points, following a $10 \%$ productivity shock in every other country in the world, and decomposes the total GDP change into the $\mathcal{E}^{F}$ and $\Gamma^{F}$ terms. The left panel reports the results for the baseline model, and the right panel for the alternative model that suppresses firm heterogeneity, for alternative parameter values. 
Table A7. Robustness: GDP Responses to a Worldwide Preference Shock in the Baseline vs. Homogeneous Models

\begin{tabular}{|c|c|c|c|c|c|c|}
\hline \multirow[t]{2}{*}{ Model: } & \multicolumn{3}{|c|}{ Baseline } & \multicolumn{2}{|c|}{ Homogeneous } & firms \\
\hline & $d \ln Y^{F}$ & $\mathcal{E}^{F}$ & $\Gamma^{F}$ & $d \ln Y^{F}$ & $\mathcal{E}^{F}$ & $\Gamma^{F}$ \\
\hline Main calibration & 0.35 & 0.19 & 0.17 & 0.38 & 0.37 & 0.02 \\
\hline \multicolumn{7}{|l|}{$\rho:$} \\
\hline high: 5 & 0.29 & 0.09 & 0.21 & 0.34 & 0.35 & -0.00 \\
\hline low:1.5 & 0.45 & 0.26 & 0.19 & 0.46 & 0.39 & 0.07 \\
\hline \multicolumn{7}{|l|}{ Frisch: } \\
\hline high: 2 & 0.58 & 0.41 & 0.16 & 0.63 & 0.61 & 0.02 \\
\hline low: 0.1 & 0.29 & 0.13 & 0.17 & 0.31 & 0.30 & 0.02 \\
\hline \multicolumn{7}{|l|}{$\eta:$} \\
\hline high: 1.5 & 0.51 & 0.27 & 0.25 & 0.54 & 0.52 & 0.02 \\
\hline low: 0.5 & 0.16 & 0.08 & 0.08 & 0.18 & 0.17 & 0.01 \\
\hline \multicolumn{7}{|l|}{$\phi:$} \\
\hline high: 1.5 & 0.36 & 0.20 & 0.16 & 0.39 & 0.37 & 0.01 \\
\hline low: 0.5 & 0.35 & 0.18 & 0.17 & 0.38 & 0.36 & 0.02 \\
\hline \multicolumn{7}{|l|}{$\sigma:$} \\
\hline high: 3 & 0.98 & 0.45 & 0.53 & 1.05 & 0.99 & 0.06 \\
\hline low: 1.1 & 0.11 & 0.06 & 0.05 & 0.12 & 0.12 & 0.00 \\
\hline Flexible markups & 0.37 & 0.19 & 0.18 & 0.38 & 0.37 & 0.02 \\
\hline $\begin{array}{l}\text { Changing profits in } \\
\text { final demand }\end{array}$ & 0.35 & 0.18 & 0.17 & 0.38 & 0.38 & 0.00 \\
\hline
\end{tabular}

Notes: This table reports the change in French GDP, in percentage points, following a 10\% foreign demand shock for French goods, and decomposes the total GDP change into the $\mathcal{E}^{F}$ and $\Gamma^{F}$ terms. The left panel reports the results for the baseline model, and the right panel for the alternative model that suppresses firm heterogeneity, for alternative parameter values. 
Table A8. Robustness: GDP Responses in the Baseline vs. Homogeneous Models

\begin{tabular}{|c|c|c|c|c|c|c|}
\hline \multirow[t]{2}{*}{ Shock: } & \multicolumn{3}{|c|}{ Productivity } & \multicolumn{3}{|c|}{ Demand } \\
\hline & Baseline & Homogeneous & Ratio H/B & Baseline & Homogeneous & Ratio H/B \\
\hline Main calibration & 2.77 & 3.39 & 1.22 & 0.35 & 0.38 & 1.08 \\
\hline \multicolumn{7}{|l|}{$\rho:$} \\
\hline high: 5 & 1.73 & 2.98 & 1.72 & 0.29 & 0.34 & 1.18 \\
\hline low: 1.5 & 3.77 & 4.03 & 1.07 & 0.45 & 0.46 & 1.02 \\
\hline \multicolumn{7}{|l|}{ Frisch: } \\
\hline high: 2 & 14.43 & 16.21 & 1.12 & 0.58 & 0.63 & 1.09 \\
\hline low: 0.1 & 0.89 & 1.26 & 1.41 & 0.29 & 0.31 & 1.07 \\
\hline \multicolumn{7}{|l|}{$\eta:$} \\
\hline high: 1.5 & 2.30 & 2.71 & 1.18 & 0.51 & 0.54 & 1.06 \\
\hline low: 0.5 & 3.40 & 4.30 & 1.27 & 0.16 & 0.18 & 1.11 \\
\hline \multicolumn{7}{|l|}{$\phi:$} \\
\hline high: 1.5 & 2.87 & 3.63 & 1.26 & 0.36 & 0.39 & 1.08 \\
\hline low: 0.5 & 2.60 & 3.07 & 1.18 & 0.35 & 0.38 & 1.08 \\
\hline \multicolumn{7}{|l|}{$\sigma:$} \\
\hline high: 3 & 0.56 & 0.92 & 1.64 & 0.98 & 1.05 & 1.07 \\
\hline low: 1.1 & 3.61 & 4.37 & 1.21 & 0.11 & 0.12 & 1.06 \\
\hline Flexible markups & 2.89 & 3.39 & 1.17 & 0.37 & 0.38 & 1.03 \\
\hline $\begin{array}{l}\text { Changing profits in } \\
\text { final demand }\end{array}$ & 3.20 & 3.77 & 1.18 & 0.35 & 0.38 & 1.11 \\
\hline
\end{tabular}

Notes: This table reports the change in French GDP, in percentage points, following a $10 \%$ productivity shock (left panel) or a $10 \%$ foreign demand shock for French goods (right panel) in every other country in the world, both in the baseline model and the alternative model that suppresses firm heterogeneity, for alternative parameter values. 